\title{
La cartografía del yiqtol corto en hebreo bíblico
}

Alexander Andrason * Stellenbosch University

En el presente artículo, el autor ofrece un análisis dinámico (cognitivo, tipológico y de gramaticalización) del yiqtol corto en hebreo bíblico. El gram, con toda su variedad de valores, se puede presentar como un fenómeno coherente por medio de una onda (un mapa sincrónico bidimensional cuyos valores están relacionados cognitivamente) con zonas de mayor o menor prototipicalidad y, por eso, semantización. El yiqtol corto se define como un gram de camino modal por contaminación, contaminado en el contexto deóntico de hablante (afirmativo y negativo), extendido después a usos subordinados de finalidad y, a continuación, empleado como futuro (primero apodótico y luego independiente). La zona de prototipicalidad corresponde a usos deónticos. El valor de finalidad constituye el pico de prototipicalidad secundario, mientras que el significado de futuro es minoritario.

Palabras Clave: hebreo bíblico; sistema verbal; semántica; lingüística cognitiva; gramaticalización.

Cartography of Short yiqtol in Biblical Hebrew.- This paper provides a dynamic (i.e. cognitive, typological and grammaticalization driven) analysis of short yiqtol in Biblical Hebrew. The author argues that short yiqtol can be understood as a coherent construction if it is modeled as a wave - a synchronic two-dimensional map whose components are related cognitively (as visualized by the $x$ axis) and specified for their degree of prototypicality (as visualized by the $y$ axis). The evidence demonstrates that short yiqtol should be classified as a gram that travels a modal-contamination path. Its contamination originated in a deontic context of speaker modality (both affirmative and negative), subsequently extended to subordinate uses (goal) and future values (first in apodoses and next in other syntactic environments). In Biblical Hebrew, the zone of prototypicality includes deontic senses. The value of goal constitutes the secondary peak of prototypicality. The sense of futurity is non-prototypical.

KeYwords: Biblical Hebrew; Verbal System; Semantics; Cognitive Linguistics; Grammaticalization.

\footnotetext{
*andrason@sun.ac.za
} 


\section{INTRODUCCIÓN: EL YIQTOL CORTO Y SU MODELO}

El yiqtol corto es una categoría verbal del hebreo bíblico que desde una perspectiva sincrónica está tradicionalmente clasificada como una forma modal deóntica, es decir, como un yusivo'. Dado su fuerte carácter modal -el gram $^{2}$ se asocia con la expresión de órdenes y consejos dirigidos a la tercera persona (yusivo propio) y con prohibiciones, especialmente dirigidas a la segunda persona (imperativo negativo)- la construcción suele analizarse como perteneciente al subgrupo modal del sistema verbal del hebreo bíblico, junto con el cohortativo (eqtalah) e imperativo (qatol). Como bloque modal, las tres formaciones se oponen a otros grams "indicativos" (qatal, yiqtol y qotel), mientras que dentro del grupo modal las tres desarrollan la siguiente red de contratos sistémicos: el eqtalah se dirige a la primera persona (cohortativo), el qatol es una forma afirmativa que se dirige a la segunda persona (imperativo), y el yiqtol corto se dirige a la tercera persona (yusivo) y, en su uso negativo, a la segunda persona (prohibitivo) ${ }^{3}$.

Desde la perspectiva de la gramaticalización, el yiqtol corto se define como una manifestación del camino modal por contaminación; es decir, como una forma inicialmente no-modal pero modalizada a raíz de su uso

${ }^{1}$ P. Joüon, Grammaire de l'hébreu biblique (Roma 1923) págs. 307 y 309-311; F. RundGren, Das althebräische Verbum: Abiss der Aspektlehre (Stockholm 1961) págs. 109110; T. O. LambDIN, Introduction to Biblical Hebrew (New York 1971) págs. 118-119; A. Loprieno, Das Verbalsystem im Ägyptischen und im Semitischen: Zur Grundlegung einer Aspekttheorie (Wiesbaden 1986) págs. 110 y 180; R. Longacre, Joseph: A Story of Divine Providence. A Text Theoretical and Textlinguistic Analysis of Genesis 37 and 39-48 (Winona Lake 1989) pág. 121; K. WALtKe y M. O. O'Connor, An Introduction to Biblical Hebrew Syntax (Winona Lake 1990) págs. 564-579; D. M. Gropp, «The function of the finite verb in Classical Biblical Hebrew», Hebrew Annual Review 13 (1991) págs. 45-62: 46-47; J. GenTRY, «The system of the finite verb in Classical Biblical Hebrew», Hebrew Studies 39 (1998) págs. 7-39; J. Joosten, «Do the finite verbal forms in Biblical Hebrew express aspect?», Journal of Ancient Near East Studies 29 (2002) págs. 49-70: 64-65; J. Joosten, The Verbal System of Biblical Hebrew (Jerusalem 2012); J. Соок, The Biblical Hebrew Verbal System: A Grammaticalization Approach (Tesis doctoral; University of Wisconsin-Madison 2002) págs. 235 y 241; J. Соoк, Time and Biblical Hebrew Verb (Winona Lake 2012).

${ }^{2}$ El término gram se refiere a cualquier tipo de construcción verbal, analítica o sintética, central o periférica, profundamente gramaticalizada o de un bajo nivel de gramaticalización.

${ }^{3}$ Waltke y O'Connor, An Introduction to Biblical Hebrew Syntax, págs. 564-579; Соок, Time and Biblical Hebrew Verb; Joosten, The Verbal System of Biblical Hebrew. 
frecuente en contextos modales explícitos. En concreto, el yiqtol corto deriva del *yaqtul protosemítico, coincidiendo genéticamente con el wayyiqtol $^{5}$. Dado que la misma morfología sirvió para grams modales y perfecto-pasados (aunque con una posible diferencia en acentuación), nos enfrentamos a una separación de la diacronía resultativa inicial (o un input resultativo) en dos itinerarios independientes: el camino resultativo y el camino modal por contaminación. Por lo tanto, el *yáqtul protosemítico del camino resultativo dio lugar al wayyiqtol en hebreo, a iprus en acadio y a lam(ma)-yaqtul en árabe, mientras que el *yaqtúl del camino modal por contaminación produjo el yiqtol corto del hebreo, el liprus y ayyiprus del acadio y el yaqtul (apocopado yusivo) del árabe. En otras palabras, en contextos modalmente neutrales la morfología *yaqtul siguió el patrón evolutivo regular previsto y, por lo tanto, se desarrolló en consonancia con las leyes de la trayectoria resultativa, convirtiéndose por tanto en perfectos, perfectivos o pasados. En cambio, en entornos modales manifiestos la formación se identificó con el matiz modal inherente al contexto en el que se hallaba (vid. Gráfico 1). Esta diferenciación funcional -pero no morfológica- es muy antigua y ya estaba establecida en época protosemítica ${ }^{6}$ (sobre la historia del *yaqtúl y su presencias en lenguas semíticas vid. aptdo. 3.2.3) ${ }^{7}$.

\footnotetext{
${ }^{4}$ A. ANDRAson, «The Dynamic Short yiqtol», Journal for Semitics $21: 2$ (2012) págs. 308339, y El sistema verbal hebreo en su contexto semítico: una visión dinámica (Estella 2013).

${ }^{5}$ Waltke y O'Connor, An Introduction to Biblical Hebrew Syntax; M. S. Sмiтн, The Origins and Development of the waw-consecutive: Northwest Semitic Evidence from Ugaritic to Qumran (Winona Lake 1991); B. KIENAST, Historische semitische Sprachwissenschaft (Wiesbaden 2001); E. LIPIŃSKI, Semitic Languages Outline of a Comparative Grammar (Leuven 2001); N. J. S. KouwENBERG, The Akkadian Verb and its Semitic Background (Winona Lake 2010); A. ANDrason, «The Akkadian Iprus from the Unidirectional Perspective», Journal of Semitic Studies 55:2 (2010) págs. 325-345; «The Dynamic Short yiqtol», y El sistema verbal hebreo en su contexto semítico.

${ }^{6}$ KIENAST, Historische Semitische Sprachwissenschaft; LIPIŃSKI, Semitic Languages Outline of a Comparative Grammar; J. HuEHNERGARD, «Afro-Asiatic», en The Ancient Languages of Syria-Palestine and Arabia, ed. R. D. WoOdARD (Cambridge 2008) págs. 225-246.

${ }^{7}$ Debe señalarse que la bifurcación de una expresión de tipo resultativo en camino resultativo y camino modal es bien conocida desde el punto de vista tipológico (cf. ANDRASON, «The Dynamic Short yiqtol»; El sistema verbal hebreo en su contexto semítico, y «An Optative Indicative? A Real Factual Past? A Cognitive-Typological Approach to the Precative qatal», Journal of Hebrew Scriptures 13:4 (2013) págs. 1-41, y A. ZABORSKI, «Big and Small Problems of the Biggest Panorama of the Semitic Languages», Brill's Annual of Afroasiatic Languages \& Linguistics 5 (2013) págs. 253-304.
} 
En consecuencia, el significado modal no era congénito al *yaqtul en la época pre-protosemítica (del que surgieron el *yáqtul y el *yaqtúl protosemíticos). Al contrario, este valor estuvo, por lo menos inicialmente, condicionado por otras entidades léxicas o por factores sintácticos. Esto significa que el yiqtol corto, por su parte, no deriva de una expresión modal de agente (obligación, deseo, aptitud), como varios modos gramaticales, sino que adquirió en hebreo su función modal y el estatus de modo -y también en época pre-protosemítica, como el *yaqtúl en el protosemítico- a través de su uso en un contexto modal explícito.

Esta definición ofrece una explicación dinámica del significado modal del yiqtol corto relacionándolo además con la morfología equivalente que ofrece el wayyiqtol. De este modo, la entera semántica del elemento (-)yiqtol en las dos formas (yiqtol corto y wayyiqtol) puede presentarse de forma coherente. Se completa así el modelo de gramaticalización del sistema verbal hebreo como un conjunto de tres caminos semánticos mayores: camino resultativo (wayyiqtol y qatal), camino imperfectivo (yiqtol largo y qotel) y camino modal de contaminación (yiqtol corto y weqatal).



Gráfico 1: Trayectoria de gramaticalización del yiqtol corto y su relación con el wayyiqtol

A pesar de sus logros, el estudio dinámico y la definición del yiqtol corto en términos de gramaticalización desarrollados hasta el día de hoy presentan una serie de limitaciones que pueden englobarse en dos bloques principales:

En primer lugar, no se ha empleado la variedad sincrónica de los valores ofrecidos por el gram para determinar el camino diacrónico que subyace a este gram. En contraste con los análisis del qatal, wayyiqtol, yiqtol

\footnotetext{
${ }^{8}$ ANDRASON, «The Dynamic Short yiqtol», y El sistema verbal hebreo en su contexto semítico.
} 
largo, weqatal y qotel, no se ha elaborado ningún mapa semántico que represente la organización cognitiva (tanto conceptual como diacrónica) del significado del yiqtol corto 9 . En otras palabras, los valores semánticos del yiqtol corto no han sido organizados en una secuencia que corresponda a consecutivas etapas del camino modal por contaminación. Esto implica que todavía no se ha respondido a la cuestión de dónde empezó dicha contaminación, ni tampoco al problema de qué significados corresponden a extensiones posteriores, secundarias o terciarias. Los estudios efectuados hasta el momento sólo han determinado que el yiqtol corto es un ejemplo de camino modal por contaminación, pero sin especificar cuáles han sido las sucesivas etapas semánticas de esa evolución.

En segundo lugar, no se ha ofrecido hasta el momento un estudio estadístico detallado de las frecuencias que presentan los diferentes significados del yiqtol corto y que especifique también el peso de cada valor en el potencial semántico del gram y su contribución a éste. Por tanto, no se ha determinado el núcleo prototípico del potencial semántico de la construcción o el centro de su mapa (que corresponden al significado más frecuente), ni las variantes radiales periféricas (que corresponden a los valores menos comunes). Esta deficiencia en términos estadísticos está relacionada con la tendencia presente, tanto en la clasificación dinámica como en los modelos tradicionales, de enfatizar la prominencia de los valores yusivos propios y del prohibitivo. Otros significados, que también se expresan por medio del yiqtol corto, como son la finalidad en frases dependientes similar al subjuntivo, el valor "apodótico" (una interpretación futura en apódosis condicional) y el futuro, han sido marginados y parecen -sin que se apoyen en un estudio estadístico riguroso- contribuir

${ }^{9}$ Sobre los mapas semánticos véanse M. Haspelmath, Indefinite Pronouns (Oxford 1997), y «The Geometry of Grammatical Meaning: Semantic Maps and Cross-Linguistic Comparison», en The New Psychology of Language, ed. M. Tomasello (Mahwah 2003) págs. 211-242; W. CROFt, Radical Construction Grammar (Oxford 2001), y Typology and Universals (Cambridge 2003); F. DE HAAN, «On Representing Semantic Maps», E-MELD Language Documentation Conference: Workshop on Linguistic Databases and Best Practice. University of Arizona, Manuscript (2004) págs. 1-12, y «Building a Semantic Map: Top-Down versus Bottom-Up Approaches», Linguistic Discovery 8:1 (2010) págs. 102-117; J. ZwarTs, «Semantic Map Geometry: Two Approaches», Linguistic Discovery 8:2 (2010) págs. 377-395, y H. NARrog y J. van DE Auwera, «Grammaticalization and Semantic Maps», en The Oxford Handbook of Grammaticalization, ed. H. NARrog y B. HeINE (Oxford 2011) págs. 318-327. 
poco a la clasificación de la formación, puesto que la modalidad deóntica es con la que generalmente se identifica el gram.

Este artículo continúa la línea de investigación que comencé en trabajos publicados en 2012 y 2013, que tratan de corregir importantes deficiencias en la comprensión del yiqtol corto. En concreto, tiene como objetivo diseñar un mapa semántico en el que varios significados del yiqtol corto se relacionen uno con otro como extensiones semánticas cognitivas o contextuales, formando una secuencia conceptual (radial) o diacrónica (de gramaticalización) desde valores (etapas) más originales a valores (etapas) secundarios y terciarios. En los dos tipos de mapas se indicará la sección prototípica que más contribuye al significado global del gram.

Con este fin, el artículo se organiza de la siguiente forma. En primer lugar, ofrecerá un estudio estadístico detallado del yiqtol corto -en particular de la morfología del yiqtol corto, que es explícitamente distinta a la del yiqtol largo- en seis libros de la biblia hebrea: Génesis, Éxodo, Levítico, Números, Deuteronomio y 1 Reyes. Se analizarán los significados del gram (se clasifica cada uso como compatible con un dominio semántico modal o temporal), sus rasgos morfológicos (diferenciaremos entre yiqtol corto "simple", que denominaremos Syiqtol", y yiqtol corto precedido inmediatamente por la partícula ı, que llamaremos WE-Syiqtol), sus entornos sintácticos (especialmente la presencia de partículas y una posible posición inicial del sujeto u objeto), sus propiedades textuales (tipo de texto), así como los contextos pragmáticos de uso (aptdo. 2). Esta información se empleará para formular un mapa cualitativo y cuantitativo del yiqtol corto en forma tanto radial (psicológica; aptdo. 3.1) como diacrónica, que ofrecerá una posible secuencialidad de los significados a lo largo de un trayecto de gramaticalización (aptdo. 3.2). Esta representación cualitativo-cuantitativa (el mapa de los valores y sus contribuciones al gram en términos de frecuencia) se presentará a continuación bajo un modelo de onda, un modelo alternativo de mapas dinámicos propuesto recientemente por Andrason, y Andrason y Visser ${ }^{11}$. Finalmente, la defini-

${ }^{10}$ El término Syiqtol es una abreviatura y hace referencia a la denominación inglesa short yiqtol (A. ANDRASON, «The Dynamic Short yiqtol»).

${ }^{11}$ A. Andrason, «Toward the Ocean of the Biblical Hebrew Verbal System», Folia Orientalia 52 (2015) págs. 15-36, y A Complex System of Complex Predicates: Tense, Taxis, Aspect and Mood in Basse Mandinka from a Grammaticalization and Cognitive 
ción dinámica nos permitirá proponer una nueva categorización del gram, junto con el weqatal, dentro de la corriente modal de contaminación y determinar su lugar dentro del sistema verbal del hebreo bíblico (aptdo. 4).

\section{EVIDENCIAS}

Tal como se ha explicado en el apartado anterior, el trabajo comenzará por el estudio empírico cualitativo-cuantitativo del yiqtol corto en seis libros de la biblia hebrea. En primer lugar, se ofrecerá información sobre el uso general del gram (número de casos, tipo de texto en el que aparecen, así como tipos morfológicos y sintácticos del gram; vid. aptdo. 2.1). En segundo lugar, se presentarán los resultados del análisis semántico (aptdo. 2.2), tanto macroscópicos (el gram en su totalidad; aptdo. 2.2.1) como microscópicos (análisis distinto para variantes morfo-sintácticas del yiqtol corto; aptdo. 2.2.2).

\subsection{Observaciones generales}

En el corpus analizado se encuentran exactamente 101 casos de yiqtol corto con morfología claramente diferenciada del yiqtol largo, como en el ejemplo (1.a) donde el verbo עלה 'subir' ofrece formas diferentes en

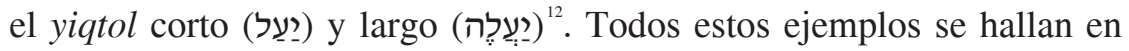
diálogos o discursos directos, nunca en partes narrativas (1.b).

Perspective (Tesis doctoral; Stellenbosch University 2016); y A. AndRASON y M. VISSER, «Affordances Perspective and Grammaticalization - Incorporation of Language, Environment and Users in the Model of Semantic Paths», Studies in Second Language Learning and Teaching 5 (2015) págs. 663-698.

${ }^{12}$ Hay que señalar que la base de datos no contiene formas del plural por razones morfológicas, ya que en estos casos la forma del yiqtol corto es indistinguible del yiqtol largo. En la determinación de las formas explícitas del yiqtol corto el buscador de dos bases de datos bien conocidas en los estudios hebreos (Lexham Hebrew Bible y Stuttgart Electronic Study Bible, ambos incluidas en el programa Logos Bible Software) no han resultado de gran ayuda ya que en múltiples ocasiones identifican como "yusivos" casos que pueden ser ejemplos del yiqtol largo o que lo son indudablemente. Además, las dos bases de datos con mucha frecuencia clasifican como yiqtol (y no como "yusivo") casos que morfológicamente son claros ejemplos de yiqtol corto. Por estas circunstancias, la 


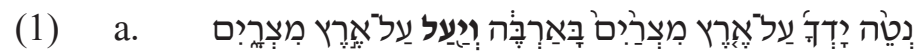

Extiende los brazos sobre todo Egipto, para que vengan langostas (Ex 10,12; N[nueva] V[ersión] I[internacional])

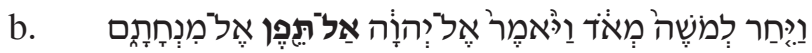

Moisés se enojó y le dijo al Señor: no aceptes la ofrenda (Nm 16,15)

Se pueden distinguir dos subtipos morfosintácticos del yiqtol corto. Uno corresponde a casos donde la construcción interviene sola, Syiqtol (2.a), mientras que el otro incluye casos en los que el gram está acompañado por el morfema we- (?), WE-Syiqtol (2.b). La primera variante es más frecuente y aparece en 71 casos (un poco más del 70\%) mientras que la segunda se presenta en 30 ejemplos (casi un 30\%).



Que haya juramento entre nosotros (Gn 26,28)

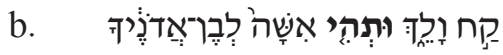

Tómela y llévesela para que sea la esposa del hijo de su amo (Gn 24,51; NVI)

Mientras que el WE-Syiqtol siempre encabeza la frase verbal y, por tanto, aparece en posición inicial absoluta, el Syiqtol puede ocupar otras posiciones y presentar en consecuencia una sintaxis más compleja. En 31 ocasiones el Syiqtol aparece en posición inicial absoluta, 0-Syiqtol (vid. ej. 3). Esto equivale a casi un $44 \%$ del Syiqtol y a casi un $31 \%$ de todos los ejemplos del yiqtol corto.



Que exista el firmamento en medio de las aguas (Gn 1,6; NVI)

Sin embargo, en 40 ocasiones (56\% del Syiqtol y casi $40 \%$ del yiqtol corto) el Syiqtol no se encuentra en posición inicial absoluta sino que aparece como $x$-Syiqtol. En concreto, el Syiqtol viene precedido por una

búsqueda de los casos de yiqtol corto se efectuó prácticamente de manera manual, analizando todos los casos que en las bases de datos mencionadas se clasifican tanto como yiqtol largo como "yusivo". 
partícula ( $p$-Syiqtol) en 22 casos. La partícula más típica es el morfema de negación אַ, que puede aparecer solo (4.a) o en compañía de otra partícula, especialmente נָָא (4.b) o (únicamente una vez) בַק (Nm 8,25). Otras


Re 1,37) לא (Gn 24,8).

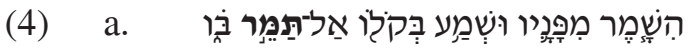

Préstale atención y obedécelo. No te rebeles contra él (Ex 23,21; NVI)

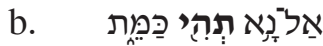

Que no sea (no la dejes) como un abortivo (Nm 12,12)

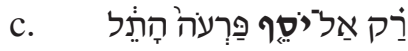

Con tal de que el faraón no nos engañe más (Ex 8,25; NVI)

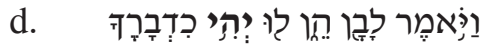

Labán dijo: está bien, que sea tal como has dicho (Gn 30,34)

En cinco ocasiones el Syiqtol viene precedido por un constituyente (c-Syiqtol). Este constituyente puede ser un objeto (5.a) o un sujeto (5.b). La primera situación ocurre cuatro veces (además del caso mencionado en el ejemplo 5.a, véanse Lv 10,9 y 5,24, así como Nm 5,7). La segunda situación se da sólo una vez.

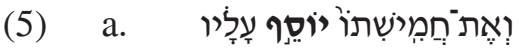

Y la quinta parte añadirá (Lev 5,16)



¡Que el Señor, el Dios de vuestros antepasados, os multiplique mil veces más! (Dt 1,11)

Además, una partícula o un constituyente pueden venir precedidos de waw, dándose las variantes morfosintácticas WE-p-Syiqtol (6.a) y WE-cSyiqtol (6.b). La secuencia WE-x-Syiqtol ocurre 9 veces. En siete casos se trata de la partícula אַל (vid. ej. 6.a) y en dos casos de la partícula עַתָָּד (6.b; el otro caso se encuentra en Gn 41,33). La secuencia WE-c-Syiqtol se atestigua cuatro veces, en las que el constituyente siempre es el sujeto; 




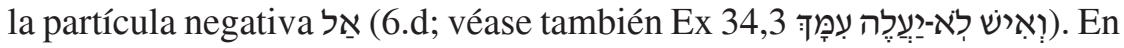
su totalidad, las partículas aparecen antes del Syiqtol (secuencia [WE]p-Syiqtol) 31 veces (31\%), mientras que los constituyentes (secuencia [WE]-c-Syiqtol) lo hacen 9 veces (9\%).

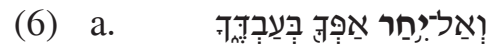

(Mi señor) no se enoje conmigo (Gn 44,18; NVI)

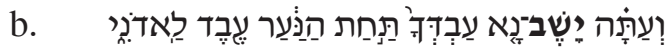

Por eso, (permita) que me quede como esclavo de mi señor (suyo) en lugar del chico (Gen 44,33)

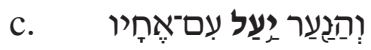

Y que él regrese con sus hermanos (Gn 44,33; NVI)

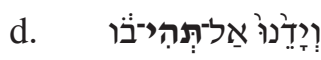

No le pongamos las manos encima (Gn 37,27)

Tal como muestran los ejemplos presentados, el yiqtol corto aparece en construcciones tanto afirmativas ( 71 casos) como negativas (30 casos). Por su parte, el WE-Syiqtol ocurre únicamente en contexto afirmativo, mientras que el Syiqtol se encuentra tanto en frases afirmativas (41 casos) como negativas (30 casos).

\subsection{Evidencias semánticas}

\subsubsection{Perspectiva global}

En este trabajo se han distinguido las siguientes categorías semánticas con las que resulta compatible el yiqtol corto: deóntico afirmativo fuerte (modalidad de obligación que expresa órdenes), deóntico afirmativo débil (modalidad de optativo que expresa deseos) ${ }^{13}$, sus variantes negativas, es decir, deóntico negativo fuerte (órdenes negativas) y deóntico negativo

${ }^{13} \mathrm{Si}$ el deóntico fuerte o débil se dirige a la $3^{\mathrm{a}}$ persona, entonces la categoría coincide con el tradicional yusivo. 
débil (deseos y ruegos negativos) ${ }^{14}$, así como modo de finalidad (expresiones de propósito similares a la modalidad sintáctica del presente de subjuntivo) y el futuro.

El deóntico afirmativo fuerte, que introduce órdenes, aparece en el $19 \%$ de los casos $(19.5 x)^{15}$. En esta función, el gram suele dirigirse a la tercera persona del singular (7.a) o a nombres colectivos (7.b). Esto ocurre 18.5 veces, lo que constituye casi el $95 \%$ de las ocurrencias del yiqtol corto con significado deóntico afirmativo fuerte. En dicha función, el Syiqtol aparece 11 veces (56\%), mientras que WE-Syiqtol lo hace 8.5 veces (casi 44\%). En ocasiones el sujeto o el objeto pueden preceder al gram (Gn 1,22; Lv 5,24; Nm 5,7).

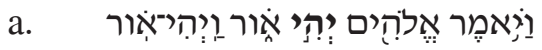

Dijo Dios: ¡Sea la luz! Y fue la luz (Gn 1,3)

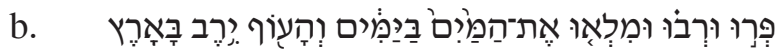

Sean fructíferos y multiplíquense, llenen las aguas de los mares. ¡Que las aves se multipliquen sobre la tierra! (Gn 1,22 ; NVI)

El orden afirmativo se dirige solo una vez a la segunda persona del singular (vid. ej. 8). Sin embargo, este caso también puede ser interpretado como modo de finalidad:

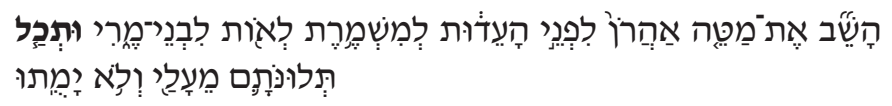

Pon de nuevo la vara de Aarón ante el testimonio, con el fin de que permanezca como advertencia para los rebeldes; deja de protestar (o de modo que dejes de protestar) contra mí y así no tengan que morir (Nm 17,25)

${ }^{14}$ El prohibitivo (que es un deóntico negativo fuerte o débil) engloba en este trabajo dos categorías tradicionales: imperativo negativo (si se dirige a la $2^{\mathrm{a}}$ persona) y yusivo negativo (si se dirige a la $3^{\text {a }}$ persona).

${ }^{15}$ En el recuento de los valores, si en un ejemplo la forma verbal de yiqtol corto ofrecía un significado no ambiguo, se le atribuía el valor 1. Sin embargo, si un ejemplo era ambiguo y ofrece dos interpretaciones posibles, a cada significado se le atribuía el valor 0.5. Esto explica que las ocurrencias de algunos significados presenten dígitos no enteros, como $18.5 \mathrm{x}$. 
El deóntico afirmativo débil, que introduce ruegos, peticiones y bendiciones y que, por tanto, se acerca al valor de la categoría de optativo, aparece en el corpus analizado casi el $30 \%$ de los casos del yiqtol corto (30x). El Syiqtol aparece 26 veces (87\% del deóntico débil), mientras que el WE-Syiqtol solo 4 veces (13\%). En dos casos el sujeto precede al verbo (Gn 44,33 y Dt 1,11). En esta función, la construcción se dirige solo a la tercena persona, de manera que no hay ejemplos con la segunda persona.

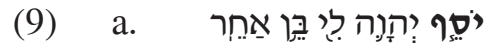

Que el Señor me añada (me de) otro hijo (Gn 30,24)

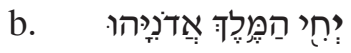

¡(Que) viva el rey Adonías! (1Re 1,25)

En total, el valor deóntico afirmativo constituye el $49 \%$ de todas las ocurrencias del yiqtol corto (49.5x). Este significado se da casi únicamente con la tercera persona. Esto ocurre 49 veces, lo que equivale a un $99 \%$. La variante Syiqtol se da en casi un 75\% (37x), mientras que el WE-Syiqtol lo hace en un 25\% (12.5x). En su empleo en $3^{\mathrm{a}}$ persona, el valor deóntico afirmativo corresponde a la categoría del yusivo.

Otro grupo de significados lo constituyen los valores deónticos negativos. Desde el punto de vista semántico, estos usos pueden entenderse como equivalentes negativos de los valores deónticos afirmativos (del tipo fuerte o débil) mencionados previamente.

En la función deóntica negativa fuerte, el gram expresa órdenes negativas. En la $2^{\mathrm{a}}$ persona equivale al imperativo negativo o prohibitivo. El significado deóntico negativo fuerte aparece en poco más del $18 \%$ de todas las ocurrencias del gram (18.5x). Con este valor el gram puede dirigirse tanto a la $2^{\mathrm{a}}$ persona ( 12.5 casos, $68 \%$ del prohibitivo fuerte; vid. ejs. 10.a-b) como a la $3^{\mathrm{a}}$ persona ( 6 casos, $32 \%$ del prohibitivo fuerte; vid. ejs. 11.a-b). En todos estos casos, el gram viene precedido de la partícula אֵל La partícula לא solo aparece en un ejemplo (Gn 24,8). Obsérvese que siempre aparece la variante Syiqtol, nunca la WE-Syiqtol ${ }^{16}$.

\footnotetext{
${ }^{16}$ Este fenómeno es obvio. La presencia de la partícula negativa delante del gram impide el uso de waw. En este contexto, no hay, por tanto, posibilidad de elegir entre una u otra opción. El uso del Syiqtol es obligatorio.
} 


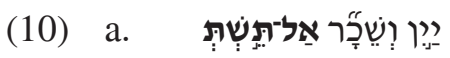

No bebas vino ni licor (Lv 10,9)

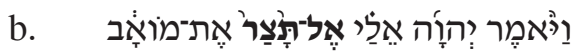

El Señor me dijo: No ataquen a los moabitas (Dt 2,8)

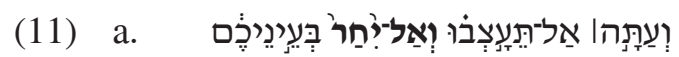

Pero ahora, por favor, no se aflijan más ni se reprochen (Gn 45,5; NVI)

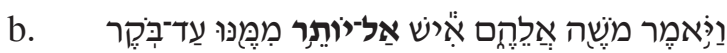

Moisés les dijo: Que nadie guarde nada para el día siguiente (Ex 16,19)

El deóntico negativo débil, que introduce peticiones o ruegos de que algo no ocurra, aparece 11 veces (casi el 11\% de todos los casos del yiqtol corto). En este uso el gram -que se presenta invariablemente en su variante Syiqtol- está siempre introducido por la partícula אַ, la cual se emplea en 7 ocasiones conjuntamente con la partícula נֵָ Este valor se da normalmente cuando el locutor se dirige a un superior (13.a), incluyendo a Dios (12.a-b), o cuando se le propone algo a una persona de similar rango en lugar de darle una orden (13.b). En esta función el gram puede dirigirse tanto a la $2^{\text {a }}$ persona ( 3 casos, $27 \%$ del prohibitivo débil; vid. ejs. 12.a-b) como a la $3^{\text {a }}$ persona ( 8 casos, $73 \%$ del prohibitivo débil; vid. ejs. 13.a-b). Por lo tanto se observa una tendencia inversa a la del valor deóntico negativo fuerte: mientras que éste se dirige con mayor frecuencia a la segunda persona, la variante débil ocurre más a menudo con la tercera persona.

(12) a.

Mi señor, no pongas sobre nosotros este pecado ( $\mathrm{Nm}$ 12,11; R[eyna]-V[alera] 1995)

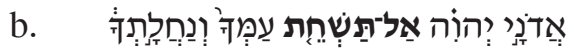

Oh Señor, Dios, no destruyas a tu pueblo y a tu heredad (Dt 9,26) 


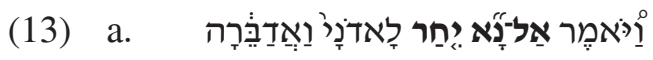

Y habló: No se enoje ahora mi Señor si le digo (Gn 18,30; RV 1995)

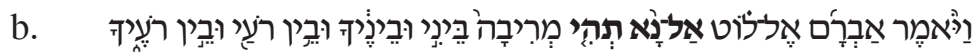
Entonces Abram dijo a Lot: No haya ahora altercado entre nosotros dos ni entre mis pastores y los tuyos (Gn 13,8; RV 1995)

En total, el significado deóntico negativo constituye el $29.5 \%$ de los casos de yiqtol corto, de los cuales el $52.5 \%$ se refieren a la $2^{\mathrm{a}}$ persona, mientras que el $47.5 \%$ conciernen a la $3^{\mathrm{a}}$ persona. Este valor nunca se da con el WE-Syiqtol ${ }^{17}$.

El valor del modo de finalidad que introduce una idea de propósito similar a la función ejercida por la modalidad sintáctica del subjuntivo constituye un poco más del 18\% (18.5x) de todos los casos del yiqtol corto. Esta función se da casi únicamente en el contexto de la $3^{\mathrm{a}}$ persona (14.a-b). El único caso posible de empleo de la $2^{\mathrm{a}}$ persona se encuentra en el ejemplo 8 mencionado previamente, que ofrece una doble lectura posible: deóntica o de finalidad. El significado de finalidad es siempre afirmativo. En 17.5 casos se trata de la variante WE-Syiqtol (95\% de este significado) mientras que el Syiqtol aparece únicamente una vez (Ex 7,9; 5\%).

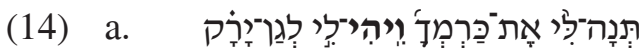

Dame tu viñedo para que yo lo convierta en una huerta de hortalizas (1Re 21,2)



Llévalo a tu casa para que coma pan y beba agua (1Re 13,18; NVI)

Además de los valores especificados previamente, el yiqtol corto puede funcionar esporádicamente como un futuro. Eso ocurre en casi el 3.5\% de los usos del gram (3.5x). Tres casos parecen presentar este valor de una manera clara y unívoca. En los tres el gram se presenta en tercera per-

${ }^{17}$ Ya que el valor deóntico negativo solo puede darse si la partícula negativa está presente, el uso de waw es inadmisible. Vid. nota 16. 
sona y en función afirmativa. En el primer ejemplo (Gn 49,17) el yiqtol corto de futuro alterna con el yiqtol largo del verso anterior (Gn 49,16); las dos formaciones se emplean en paralelo:

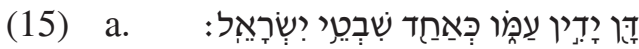

Dan juzgará a su pueblo, como una de las tribus de Israel

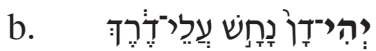

Dan será serpiente junto al camino (Gn 49,16-17; RV 1995)

Un ejemplo similar se encuentra en Dt 28,8. El Syiqtol se usa en paralelo con otras formas verbales con el significado de futuro; el yiqtol largo

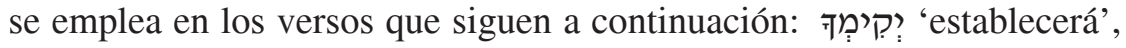

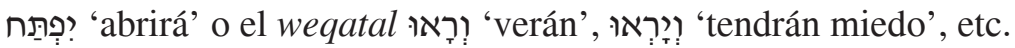

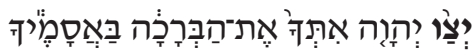

El Señor tu Dios bendecirá tus graneros (Dt 28,8; NVI)

El tercer caso de yiqtol corto de futuro corresponde al uso del gram en una apódosis condicional (vid. ej. 17). Aunque el valor prospectivo -espacialmente, en comparación con la acción expresada en la prótasis- es evidente ('añadirán'), también es posible que se de un matiz de necesidad (siempre futura), 'tendrán que / deberán añadir':

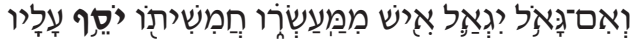

Si alguien desea rescatar algo de su diezmo, añadirá (cf. RV 1995; véase también New Life Version 'he will add'; Revised Standart Version 'he shall add' o International Standart Version 'he is to add') a su valor una quinta parte (Lv 27,31; véase NVI 'deberá añadir'; Nueva Traducción Viviente ‘tendrás que pagar’)

En un caso puede darse una doble interpretación: una con valor de prohibitivo fuerte, otra con función de futuro apodótico (vid. ej. 18). Por lo tanto, el yiqtol corto de futuro se dirige normalmente a la tercera persona y suele ser afirmativo ( $86 \%$ de este tipo semántico del gram). El uso negativo, dirigido a la segunda persona, es posible en un $14 \%$ del yiqtol 
corto de futuro. En 1.5 ocasiones se trata de un uso apodótico, mientras que en dos casos se trata del futuro "independiente".

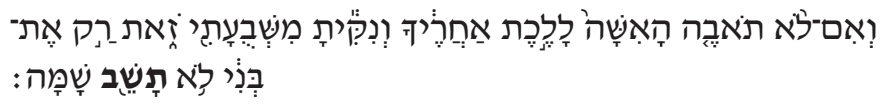

Si la mujer no está dispuesta a venir contigo, quedarás libre de este juramento; pero ¡en ningún caso llevarás a mi hijo hasta allá! (Gn 24,8; NVI)

Se puede afirmar, en conclusión, que la modalidad de tipo deóntico (afirmativo y negativo) tiene mayor peso en el potencial semántico del yiqtol corto y constituye un $78 \%$ de las ocurrencias del gram (79x). Casi un $63 \%$ del deóntico es afirmativo (49.5x), mientras que un $37 \%$ es negativo (29.5). En casi un 16\% (12.5x) aparece la variante WE-Syiqtol, mientras que en un $84 \%$ se trata del Syiqtol. El yiqtol corto deóntico afirmativo y negativo se dirige a la $3^{\mathrm{a}}$ persona en un $80 \%$ de los casos, mientras que sólo en un $20 \%$ a la $2^{\mathrm{a}}$ persona. Los otros dos valores (finalidad y futuro) suponen en conjunto un $22 \%$, el modo de finalidad casi un $18.5 \%$ y el futuro un $3.5 \%$. Los dos son típicamente afirmativos y se dirigen a la $3^{\mathrm{a}}$ persona. Tal como se ha mencionado, el primero ocurre casi siempre (95\%) con el WE-Syiqtol, mientras que el segundo invariablemente emplea la variante Syiqtol. Si todos los valores modales se consideran de manera conjunta -la modalidad deóntica y la de finalidad o subjuntivaestos constituyen un 96.5\% (97.5x). La "no-modalidad", en este caso el futuro -sea apodótica o independiente- equivale a un $3.5 \%(3.5 \mathrm{x})$.

\subsubsection{Frecuencias microscópicas}

En el apartado anterior hemos presentado datos globales, en particular los valores semánticos y sus frecuencias para el yiqtol corto, como una sola categoría compacta. En este apartado se presentarán, por separado, las evidencias semánticas (significados y su distribución estadística) referidas a dos tipos de yiqtol corto, el WE-Syiqtol y el Syiqtol, y se analizarán, además, tres subvariantes de este último: a) 0-Syiqtol; b) x-Syiqtol (i.e. $p$-Syiqtol y $c$-Syiqtol) y c) WE- $x$-Syiqtol (i.e. WE-p-Syiqtol y WE-cSyiqtol). 


\section{A. Syiqtol}

El Syiqtol aparece 71 veces en el corpus considerado, siendo una variante más común que el WE-Syiqtol (véase a continuación). En conjunto, el Syiqtol presenta el siguiente potencial semántico: deóntico afirmativo fuerte 14\% (10x), deóntico afirmativo débil 38\% (27x; el deóntico afirmativo constituye, en general, un 52\%), deóntico negativo fuerte $27.5 \%$ (19.5x), deóntico negativo débil 14\% (10x; deóntico negativo equivale, en general, a un $41.5 \%)$, futuro $5 \%(3.5 \mathrm{x})$, finalidad $1.5 \%(1 \mathrm{x})$. Se pueden distinguir tres subtipos de Syiqtol: 0-Syiqtol (Syiqtol en posición inicial absoluta), $x$-Syiqtol (Syiqtol precedido por una partícula $p$-Syiqtol o un constituyente [sujeto u objeto] $c$-Syiqtol) y WE- $x$-Syiqtol (un $x$-Syiqtol precedido adicionalmente por la partícula waw).

La variante 0 -Syiqtol ocurre 31 veces, lo que equivale al $31 \%$ del yiqtol corto en su conjunto y a casi el $44 \%$ del Syiqtol. Este tipo de Syiqtol expresa un significado deóntico afirmativo 27 veces, es decir, en un $87 \%$ $(68 \%$ de la variante débil $[21 x]+19 \%$ de la fuerte $[6 x])$. El valor del futuro asciende a casi un 10\% (3x) del potencial semántico del 0-Syiqtol, mientras que el modo de finalidad lo hace a un $3 \%(1 \mathrm{x})$.

El $x$-Syiqtol ocurre 27 veces, lo que equivale al $27 \%$ de los casos de yiqtol corto o a un $38 \%$ del Syiqtol. Predomina la variante con partícula, el p-Syiqtol, que constituye un 22\% (22x) del yiqtol corto en su totalidad (31\% del Syiqtol y $81 \%$ del $x$-Syiqtol). La variante $c$-Syiqtol se encuentra en 5 ocasiones, lo que equivale al $5 \%$ del yiqtol corto (7\% del Syiqtol y $19 \%$ del $x$-Syiqtol). El p-Syiqtol se emplea típicamente en función deóntica negativa: 19.5 veces ( $89 \%$ de su potencial semántico; la variante fuerte se halla 11 veces y la débil 8 veces). Los valores del deóntico afirmativo ascienden a un $9 \%(2 x)$. En un caso se puede interpretar como futuro, además de como deóntico negativo fuerte, que también es admisible. El subtipo c-Syiqtol suele emplearse como deóntico: $80 \%$ (cuatro casos, de los cuales tres son del tipo afirmativo fuerte y uno del tipo afirmativo débil) de su potencial semántico. El valor deóntico negativo equivale al $20 \%(1 \mathrm{x})^{18}$. En conjunto, el significado deóntico negativo es el más importante en el $x$-Syiqtol y equivale a un $76 \%$. El valor deóntico afirmativo

\footnotetext{
${ }^{18}$ Este caso también está marcado por una particula negativa (Lv 10,9).
} 
constituye un $22 \%$ y el futuro aproximadamente un $2 \%$. No hay ejemplos con valor de finalidad.

El WE- $x$-Syiqtol se da en 13 casos, lo que equivale al 13\% del yiqtol corto y al $18 \%$ del Syiqtol. Esta variante (al igual que el $x$-Syiqtol) presenta dos subtipos: WE-p-Syiqtol (9x, 13\% del Syiqtol y 69\% del WE- $x$ Syiqtol) y WE-c-Syiqtol (4x, $6 \%$ del Syiqtol y $31 \%$ del WE- $x$-Syiqtol). El WE-p-Syiqtol se emplea generalmente en la función deóntica negativa ( $7 \mathrm{x}$ o $78 \%$ de su potencial semántico; la variante fuerte aparece cinco veces, mientras que la débil lo hace en dos ocasiones). El valor deóntico afirmativo (típicamente débil) constituye un 22\% (2x). La secuencia WEc-Syiqtol aparece en el 50\% de sus ocurrencias como deóntico afirmativo, débil o fuerte $(2 \mathrm{x})$, y en el otro $50 \%$ como deóntico negativo, siempre fuerte $(2 \mathrm{x})^{19}$. En estos casos el sujeto siempre se antepone al verbo.

La cuantificación conjunta de los tipos p-Syiqtol y WE-p-Yiqtol por un lado, y del $c$-Syiqtol y WE-c-Syiqtol por el otro, produce la siguiente estructura del potencial semántico: el (WE-)p-Yiqtol presenta valor deóntico negativo en un $91 \%$ (26.5x), deóntico afirmativo en un $7 \%(2 \mathrm{x}), \mathrm{y}$ futuro en un 2\% (0.5). El (WE-)c-Yiqtol expresa el significado deóntico afirmativo en un 67\% (6x) y deóntico negativo en un 33\% (3x).

\section{B. WE-Syiqtol}

Tal como se ha expuesto en el apartado 2.1, el WE-Syiqtol aparece 30 veces, lo que equivale a casi un $30 \%$ del yiqtol corto. Esta vez predomina el significado de finalidad (17.5 veces o $58 \%$ del potencial semántico del WE-Syiqtol), mientras que el valor deóntico afirmativo es menos común $-12.5 x$ ( $8.5 x$ del deóntico fuerte y $4 x$ del deóntico débil) casi un 42\%-. El significado deóntico negativo no aparece nunca ${ }^{20}$.

En conclusión, puede observarse una tendencia inversa entre los dos tipos principales del yiqtol corto: el Syiqtol se emplea normalmente en función modal deóntica en un $93.5 \%$ de los casos (deóntico afirmativo $52 \%$ y negativo $4.5 \%$ ), mientras que el modo de finalidad constituye

\footnotetext{
${ }^{19}$ En estos casos la expresión tambien incluye la partícula de negación.

${ }^{20}$ Esta conclusión es obvia. La presencia de la partícula negativa delante del gram impide el uso de waw. Por tanto, es estructuralmente posible que WE-Syiqtol tenga valor deóntico negativo.
} 
solo el 1.5\%. El WE-Syiqtol se usa típicamente en la función de finalidad (58\%), mientras que el modo deóntico desciende a un 42\%. El deóntico negativo solo se atestigua en el Syiqtol.

\section{DisCUSIÓN}

Después de haber presentado los datos que se refieren al significado del yiqtol corto -desde perspectivas tanto macro como microscópica- diseñaremos un mapa cognitivo que englobe y explique el potencial semántico del gram. Primero desarrollaremos un mapa radial estático y, a continuación, un mapa dinámico de gramaticalización (3.1), cuya última representación cualitativo-cuantitativa será una onda (3.2).

\subsection{El mapa estático (radial)}

Un mapa radial estático es una manera de coordinar los diferentes significados que puede expresar una forma gramatical. Consiste en relacionar todos los valores como extensiones radiales desde el centro del mapa; éste último corresponde al significado más prototípico, que en lingüística de corpus está normalmente correlacionado con el uso más frecuente (a veces más básico en términos cognitivos). Las extensiones reflejan, conforme se alejan del núcleo, variaciones en el significado del valor central. Aunque el mapa radial sea una forma visual muy intuitiva de encapsular la variabilidad semántica del gram (sin proponer ninguna aberración como un significado inherente invariable típico en modelos estructuralistas y neo-estructuralistas) sólo tiene dimensión sincrónica. Esta dimensión suele corresponder a la percepción del potencial semántico por parte de los hablantes; la visualización refleja la manera con la que los hablantes perciben el gram. Se trata, pues, de un mapa psicológico del gram. Dado que en el caso del hebreo bíblico no podemos tener acceso a los hablantes y, en consecuencia, conocer claramente su percepción de la forma, la representación radial debe basarse en datos estadísticos, desde el valor más frecuente (prototípicamente asociado con el gram) hacia valores gradualmente menos comunes, periféricos, relacionados conceptualmente -como extensiones contextuales- con los valores más céntricos. 
Teniendo en cuenta los resultados del estudio empírico del corpus, es posible diseñar el siguiente mapa radial. El valor deóntico afirmativo en sus dos subtipos, fuerte y débil, constituye el indudable centro del mapa (49\%: fuerte $18.5 \%$ y débil $30 \%$ ), casi siempre dirigido a la $3^{\mathrm{a}}$ persona. Su variante negativa (29\%: fuerte $18 \%$ y débil $11 \%$ ) correspondería a una extensión del significado deóntico a contextos negativos y constituye una radiación semánticamente muy relacionada con el núcleo. El valor deóntico afrimativo puede dirigirse tanto a la $2^{\mathrm{a}}$ como $3^{\mathrm{a}}$ persona casi por igual, mientras que el deóntico negativo se dirige sólo a la $3^{\text {a }}$ persona. Además, mientras que el significado deóntico afirmativo aparece con más frecuencia de manera independiente (el 0-Syiqtol constituye casi el 55\% del deóntico afirmativo [27x de los $49.5 \mathrm{x}$ ]) que con una partícula (el $x$-Syiqtol equivale a un 20\% [10x de los 49.5x] $)^{21}$, el valor deóntico negativo ofrece una situación inversa: en esta función el gram se encuentra siempre precedido por una partícula: en un 97\% por אַ y en un 3\% (una vez) por לאל 22.

En realidad, el deóntico negativo de la $3^{\text {a }}$ persona (14\%) podría entenderse como una primera radiación del núcleo yusivo. Se trata pues del mismo valor, solo que diferenciado por el contexto negativo. El deóntico negativo de la $2^{\text {a }}$ persona -el imperativo (15\%)- formaría una extensión más periférica, desde el deóntico negativo de la $3^{\mathrm{a}}$ persona a la $2^{\mathrm{a}}$ persona.

El valor de finalidad corresponde a una extensión desde el centro del mapa (valor deóntico afirmativo) donde la necesidad (fuerte o débil) se reinterpreta como el objetivo o propósito que el sujeto va a perseguir, porque lo necesita (18.5\%). Se trata solo del uso afirmativo y siempre va dirigido a la $3^{\text {a }}$ persona, lo cual se ajustaría a las propiedades de su input conceptual, el núcleo deóntico afirmativo. El 95\% de los casos del valor de finalidad lo conforma una contextualización a través del morfema waw, es decir, WE-Syiqtol.

Finalmente, el significado de futuro (3.5\%) corresponde a una extensión desde el valor de finalidad -en el que la situación o evento, al igual que en un futuro, se presentan como hechos prospectivos, todavía no cumplidos pero posibles de realizar- a una futuridad sensu stricto. De

\footnotetext{
${ }^{21} \mathrm{El}$ restante $25 \%$ corresponde al WE-Syiqtol (12.5x de los 49.5x).

${ }^{22}$ De hecho no hay otra opción. Para valor deóntico negativo es necesario el uso de una partícula negativa.
} 
esta manera, el matiz de necesidad u objetivo presente en el uso de finalidad, así como el fuerte condicionamiento sintáctico (frases dependientes y el uso del waw) cederían lugar a una interpretación más temporal y al uso independiente: el gram aparece en la forma Syiqtol y siempre en frases matrices. Sin embargo, en un 43\% (1.5x de los 3.5x) se trata del uso apodótico donde el significado futuro puede además tener un ligero matiz modal. Una vez más se trata de un uso principalmente afirmativo y dirigido a la $3^{\text {a }}$ persona ( $86 \%$; existe un ejemplo ambiguo donde el gram aparece en la $2^{\mathrm{a}}$ persona y en frase negativa). El mapa completo podría representarse de la siguiente manera, donde el tamaño de los óvalos, que representan los valores del yiqtol corto, se corresponde con su peso estadístico en el potencial del gram:

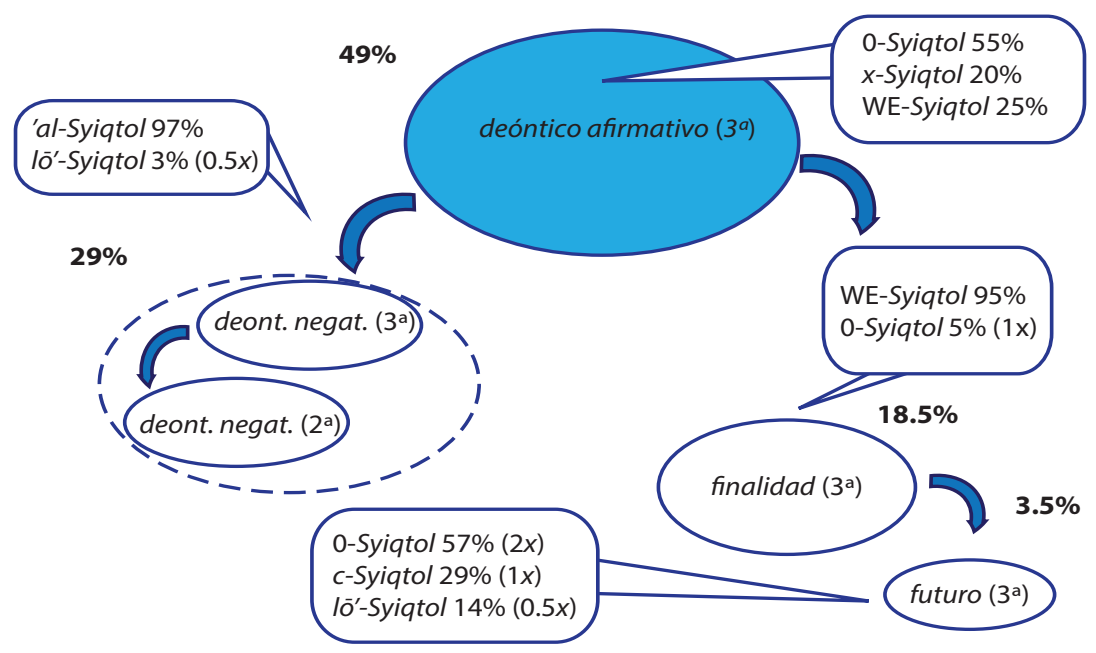

Gráfico 2: Mapa radial del yiqtol corto

Si los dos subtipos morfológicos se analizan por separado, entonces los mapas resultan bastante distintos. En líneas generales, el Syiqtol se aproxima al mapa del yiqtol corto macroscópico, pero con una diferencia: el valor de finalidad (1.5\%) es menos común que el de futuro (5\%), aunque los dos sean marginales. El significado deóntico afirmativo constituye el centro del mapa (52\%), del que parte el valor deóntico negativo $(41.5 \%)$, de dos tipos ( $3^{\mathrm{a}}$ y $2^{\mathrm{a}}$ persona) y de un peso estadístico muy 
similar (19.5\% y $21.5 \%)$. Dado que en este mapa el significado futuro es más relevante que el de finalidad, el segundo podría entenderse como una extensión del primero. En este caso, el valor futuro constituiría una extensión directa desde el deóntico afirmativo (de hecho, la variante más frecuente en los dos significados es el 0-Syiqtol), mientras que el valor de finalidad correspondería a una extensión secundaria, desde el futuro hacia contextos dependientes y con waw.

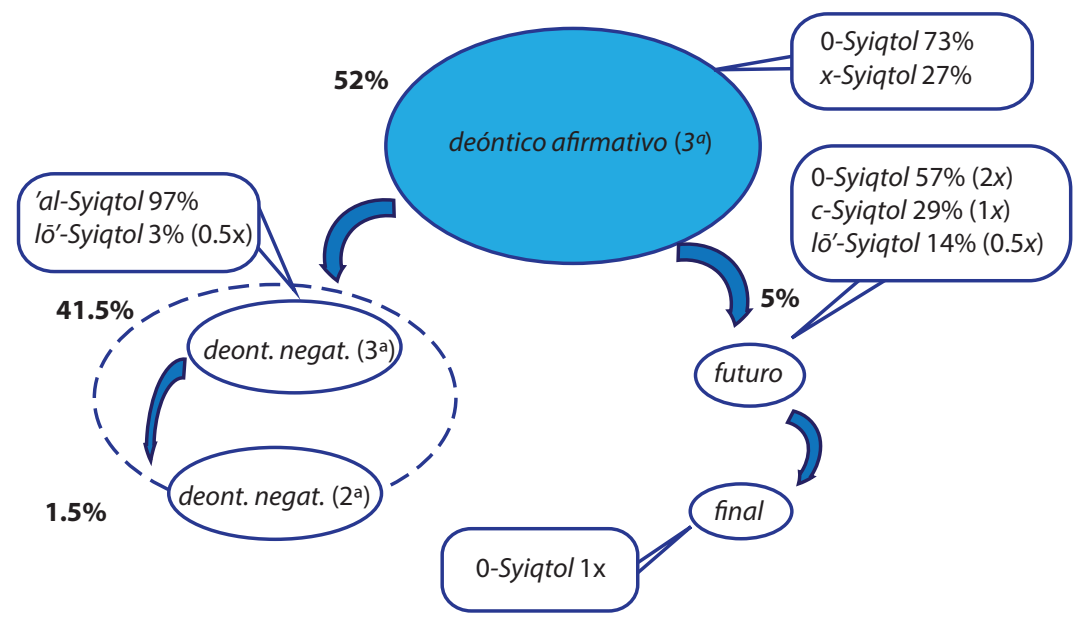

Gráfico3: Mapa radial del Syiqtol

Por contra, el WE-Syiqtol tiene un mapa topológicamente muy reducido y ofrece únicamente dos valores. El centro está formado por el significado de finalidad (58\%) y su radiación deóntica afirmativa (42\%). En este caso, la relación conceptual entre los dos significados sería inversa a la de los dos mapas diseñados previamente, es decir, desde el valor de finalidad (núcleo) hacia su extensión radial, el valor yusivo (ligeramente periférico).

La representación radial -especialmente la del yiqtol corto macroscópico y la del WE-Syiqtol- muestran claramente que el dominio de finalidad tiene un peso dentro del potencial semántico del gram bastante más relevante que el tradicionalmente adscrito. El yiqtol corto es mucho más que modalidad deóntica afirmativa o negativa, ya que un $22 \%$ de su 


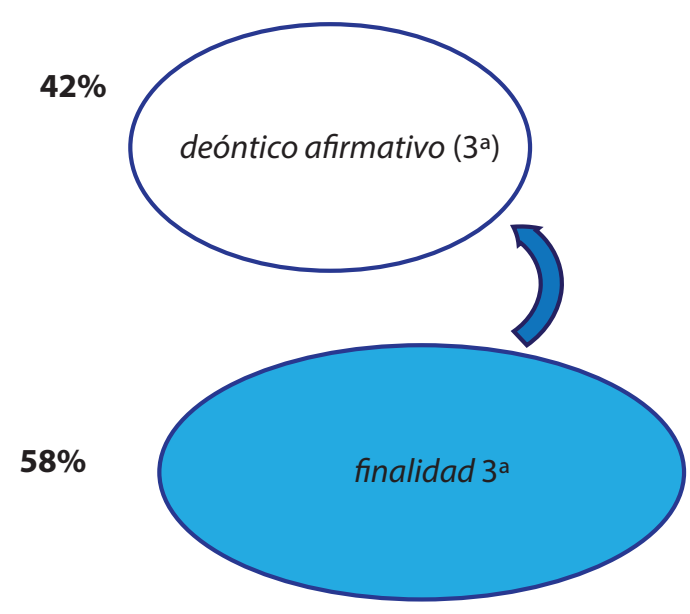

Gráfico 4: Mapa radial del WE-Syiqtol

uso no corresponde a dicho dominio semántico, sino más bien al valor de finalidad. En el caso del WE-Syiqtol la relevancia de este significado resulta aún más visible, puesto que es el valor de finalidad el que puede entenderse como centro semántico del gram.

El mapa radial ofrece dos ventajas primordiales que no estaban incluidas en el modelo de gramaticalización propuesto previamente (relación conceptual de los significados que forman el potencial semántico y determinación de su peso estadístico) y además presenta beneficios que no existían en las definiciones estructuralistas o pre-cognitivas (una definición que englobe la variación semántica y renuncie al dogma del valor inherente-invariable). También se adapta bien a un empleo pedagógico. Sin embargo, este tipo de representación tiene limitaciones.

El problema principal que presenta este tipo de mapas es que son posibles varias organizaciones, ya que los valores se organizan de una manera sincrónica y psicológica, partiendo de un significado principal central y más semantizado (prototípico) y yendo hacia valores periféricos, gradualmente menos comunes y más pragmáticos (menos prototípicos). La forma del mapa se encuentra fuertemente condicionada por la frecuencia, que es un indicador mayor de prototipicalidad (y en el caso de lenguas muertas, casi el único), lo que resulta obvio si se compara el mapa del yiqtol corto 
con el mapa del Syiqtol y especialmente con el mapa del WE-Syiqtol. De hecho, los mapas del yiqtol corto y Syiqtol no solo resultan distintos topológicamente del mapa del WE-Syiqtol, sino que sus centros son diferentes y por este motivo -y esto es más preocupante- las relaciones conceptuales de extensión son opuestas. Además, la organización topológica misma -aunque se base en las evidencias estadísticas y refleje, en consecuencia, la prototipicalidad de los valores- es psicológica. Por ejemplo, en el Gráfico 1, la posición de los valores de finalidad y futuro es muy subjetiva, dado que, siendo muy periféricos, podrían emanar desde extensiones secundarias (valores más prototípicos que ellos mismos pero menos prototípicos que el centro) o directamente del centro del mapa. Dado el peso estadístico, la relación mutua semántica entre los significados de futuro y finalidad, así como sus contextos morfosintácticos, se han propuesto dos topologías. Para el yiqtol corto: deóntico > finalidad > futuro (Gráfico 1); para el Syiqtol: deóntico > futuro > finalidad (Gráfico 2). Además, en principio también sería posible una tercera topología: deóntico $>$ futuro y deóntico > finalidad (es decir, desde el centro hacia dos radiaciones secundarias independientes).

Estas circunstancias se deben a que, a pesar de su base empírica (frecuencias que determinan el centro prototípico y las radiaciones periféricas), varios elementos en la forma del mapa radial son en realidad explicaciones subjetivas, basadas en intuición del investigador. Además, si los significados se unen en bloques mayores (o al contrario, se dividen en valores más fragmentarios), la estructura del mapa cambiará, porque las frecuencias se contabilizarán de modo distinto, ofreciendo una nueva posición del centro y de las radiaciones periféricas. En conjunto, no existe una matriz basada en datos empíricos verificables en el que un mapa radial psicológico pueda plasmar el potencial semántico de un gram (en nuestro caso, del yiqtol corto o de cualquiera de su variantes morfo-sintácticas) de una manera plenamente objetiva. Por eso, aunque un mapa como el del Gráfico 1 sea muy aplicable a la enseñanza del hebreo bíblico, ya que ayuda a los estudiantes a entender y memorizar el significado del gram en su totalidad, así como los parámetros (contextos) de sus usos (o de la activación de significados dados), esta representación no puede considerarse plenamente satisfactoria.

SEFARAD, vol. 76:1, enero-junio 2016, págs. 7-53. ISSN: 0037-0894. doi: 10.3989/sefarad.016.001 


\subsection{El mapa y onda dinámicos (diacrónicos)}

Otra manera de coordinar los componentes del potencial semántico de un gram para diseñar un mapa coherente consiste en emplear caminos diacrónicos, llamados paths en inglés. En este caso, son las trayectorias evolutivas -tipológicamente plausibles y sumamente regulares (casi o estadísticamente universales) - las que se emplean como matrices del orden interno de una polisemia. La ventaja primordial de este método radica en que dichas matrices o caminos se han derivado empíricamente y constituyen un tipo de universales lingüísticos. Esto las convierte en objetivas. Por tanto, la reestructuración de los componentes del potencial semántico se basa en matrices que no son psicológicas y subjetivas, sino empíricamente verificadas. Además estas matrices son capaces de relacionar valores de un gram que intuitivamente (tanto para los hablantes como para los gramáticos) no lo son, ya que les separa una gran distancia conceptual y diacrónica.

En términos generales, un mapa del potencial semántico de este tipo -al que llamaremos dinámico para diferenciarlo del mapa radial estáticorefleja la estructura de un trayecto diacrónico que codifica cómo determinados tipos de polisemia emergen y se desarrollan en lenguas del mundo adquiriendo paulatinamente nuevos significados. El camino es una esquematización del patrón evolutivo según el cual ciertos tipos de grams adquieren nuevos valores en un orden bien definido. El orden de esta adquisición (que es un principio diacrónico) se emplea a su vez para relacionar de una manera unidireccional los elementos de un potencial semántico sincrónico dado y presentarlo así como una composición cognitivamente coherente (tanto conceptual como diacrónicamente). Sin embargo, aunque la cohesión de los significados adyacentes (que corresponden a etapas consecutivas inmediatas) sea conceptual y la relación semántica de extensión sea visible, la cohesión del mapa entero es esencialmente diacrónica y emerge de la reiteración de las cohesiones conceptuales adyacentes. Eso explica la posibilidad de llegar a valores que, alejados bastante uno del otro, no ofrecen relación semántica o cognitiva directa; con este fin, resulta necesaria una cadena de etapas intermedias.

Hay que observar que, en un momento histórico concreto, pueden darse simultáneamente varios valores correspondientes a diferentes etapas de adquisición. Esto quiere decir que el gram no salta de una etapa a otra, sino que 
acumula significados de acuerdo a la dirección establecida por la trayectoria de gramaticalización según la cual se desarrolla esta construcción ${ }^{23}$.

Finalmente debe subrayarse que aunque los mapas dinámicos normalmente se organizan en conformidad con los caminos de gramaticalización tipológicos, dada la fuerza empírica y regularidad de estos, el mapa dinámico de un gram concreto refleja sobre todo su propio (es decir de este gram) proceso de gramaticalización. Por tanto, aunque basado en leyes tipológicas, el mapa dinámico de una forma concreta en una lengua dada es principalmente real y visualiza el camino según cual esta construcción ha evolucionado realmente. Como se ha señalado, los caminos de gramaticalización son casi universales, siendo tendencias extremadamente regulares. No obstante, estas trayectorias pueden distorsionarse en algunas ocasiones, por razones ligadas a la estructura del sistema al que se aplican $\mathrm{y}$ al hecho de que varias pueden operar conjuntamente a la vez. Esto tiene su origen en la inmensa complejidad de la lengua y de su funcionamiento como un sistema complejo ejemplar en el sentido de la teoría de la complejidad. Por eso, un mapa derivado de la variedad de los significados ofrecidos sincrónicamente y organizado según un patrón universal debe siempre corroborarse por (o modificarse a través de) evidencias diacrónicas especificas del gram que se estudia.

\subsubsection{Camino modal por contaminación}

Tal como establece la reconstrucción de la gramaticalización del yiqtol corto, este gram emergió siguiendo el camino modal de contaminación del pre-proto-semítico *yaqtul, coincidiendo genéticamente con otro gram, el wayyiqtol. Mientras que el *yaqtul "normal" evolucionó (probablemente como *yáqtul) en un gram de diacronía resultativa -es decir, siguiendo el camino resultativo se convirtió en un perfecto, perfectivo o pasado-, la variante empleada en contextos modales explícitos se contaminó modalmente produciendo el *yaqtúl y a continuación el yiqtol corto hebreo ${ }^{24}$.

${ }^{23}$ Andrason, «Toward the Ocean of the Biblical Hebrew Verbal System», y A Complex System of Complex Predicates.

${ }^{24}$ AndRason, «The Dynamic Short yiqtol», y El sistema verbal hebreo en su contexto semítico. 
Este tipo de modalización, y especialmente de bifurcación de unas formas indicativas resultativas que tuvieron su origen en una diacronía resultativa y en una diacronía modal de contaminación, es relativamente común tipológicamente ${ }^{25}$. Durante este desarrollo, formaciones originalmente indicativas se contaminan debido a su empleo en contextos claramente modales, de manera que asumen gradualmente el significado inherente del entorno en el que aparecen. Es difícil -si no imposibledistinguir etapas discretas de la contaminación modal. Se trata más bien de un proceso continuo y difuso (fuzzy) donde el gram pierde su carácter indicativo e incrementa, de una manera inversamente proporcional, su naturaleza modal, convirtiéndose finalmente en un modo gramatical. En otras palabras, se trata de un continuo desde el polo de indicatividad (un gram indicativo en $100 \%$ de los casos) hacia el polo de modalidad (un gram modal en $100 \%$ de los usos). Al final de esta evolución el gram se identifica plenamente con el valor prototípico de su contexto modal, reanalizándose como un modo; momento en el cual o bien no resulta posible su empleo en entornos no-modales o bien los usos modal y no modal se bifurcan en dos construcciones separadas. Además, el uso modal se extiende paulatinamente hacia nuevos contextos, incluyendo entornos sin marcas modales explícitas, es el gram mismo el que conlleva el significado modal en la frase. Este fenómeno corresponde a la idea de conventionalization of implicature en Dahl $^{26}$ y en Bybee, Perkins y Pagliuca ${ }^{27}$, al concepto de context-induced reinterpretation en Heine, Claudi y Hünnemeyer ${ }^{28}$ y a la noción de 'semantization' propuesta por Hopper y Traugott ${ }^{29}$.

Todo esto significa que el trayecto de contaminación modal es una diacronía cualitativamente distinta de los demás caminos diacrónicos, los cuales se componen de múltiples etapas (seguramente también difusas) correspondientes a diferentes significados (véase, por ejemplo, el camino

${ }^{25}$ Andrason, «The Dynamic Short yiqtol», y ZaBorski, «Big and Small Problems of the Biggest Panorama of the Semitic Languages».

${ }^{26}$ Ö. DAHL, Tense and Aspect Systems (Oxford 1985) pág. 11.

${ }^{27}$ J. Bybee, J. R. Perkins y W. Pagliuca, The Evolution of Grammar (Chicago 1994) págs. 25-26 y 296.

${ }^{28}$ B. Heine, U. Claudi y F. Hünnemeyer, Grammaticalization. A Conceptual Framework (Chicago 1991) págs. 71-72.

${ }^{29}$ P. Hopper y E. Traugott, Grammaticalization (Cambridge 2003) pág. 82. 
resultativo: resultativo propio $>$ perfecto $>$ pasado perfectivo $>$ pasado simple). En el caso de la contaminación modal, se trata más bien de un universal diacrónico que, en lugar de especificar los valores que se acumulan, presenta el mecanismo general que rige la vida del gram. Por eso, puede englobar varios tipos de evoluciones concretas durante las que intervienen diferentes valores, contextos y potenciales semánticos. En consecuencia, la trayectoria modal por contaminación, así presentada -es decir, como un continuum desde el polo indicativo hasta el polo opuesto modal- no se adapta bien para plasmar en un mapa los significados de un gram, especialmente si los únicos valores son los valores modales. Aunque esta matriz explique cómo apareció el yiqtol corto y de qué manera se relaciona con el wayyiqtol, no puede, en cambio, organizar el potencial semántico de la construcción. Para este fin se necesita investigar la naturaleza (el origen y secuencialidad) de los caminos modales propios y no-contaminados.

\subsubsection{Evolución de los modos: caminos modales genuinos}

Los caminos modales propios (modal paths) proporcionan el esquema evolutivo de las formaciones modales que emergen de locuciones modales originales. Durante su evolución estos grams siguen trayectos en los que se pueden distinguir varias etapas semánticas distintas. El primer cambio consiste en la trasformación de diversos tipos de modalidades del agente (agent-oriented modality) -como aptitud (por ejemplo soy capaz o puedo), obligación (por ejemplo tengo que o debo) y deseo (por ejemplo quiero)- en modalidades del hablante (speaker-oriented modality). Así pues, las expresiones del modo agentivo iniciales adquieren una función deóntica afirmativa (imperativa [con la $2^{\mathrm{a}}$ persona], yusiva [ $3^{\mathrm{a}}$ persona], cohortativa [ $1^{\mathrm{a}}$ persona] o deóntica negativa [especialmente el imperativo negativo]). La segunda novedad corresponde a una adquisición simultánea del valor de modalidad epistémica de posibilidad (puede que llueva) o probabilidad (debe haber llovido). Posteriormente, las modalidades epistémicas y del hablante incorporan funciones de futuro (posiblemente acompañadas primero por un matiz modal) para finalmente sobrevivir en usos subordinados como modalidad sintáctica de subjuntivo ${ }^{30}$.

${ }^{30}$ Bybee, Perkins y Pagliuca, The Evolution of Grammar, pág. 241. 
Por tanto, la generalización de usos modales en frases subordinadas y especialmente la constitución de la categoría gramatical de subjuntivo suelen corresponder a etapas muy avanzadas de la evolución modal ${ }^{31}$. Debe observarse que las modalidades sintácticas (que luego evolucionarán hacia el subjuntivo) al principio se armonizan con verbos introductorios que expresan algún valor modal de agente o de finalidad (querer, desear, ordenar, etc.). Gradualmente, el uso se va extendiendo a otros predicados, pudiendo hallarse en frases introducidas por verbos que no tengan ninguna fuerza modal propia ${ }^{32}$. Otro contexto típico de generación de subjuntivos corresponde a frases condicionales, sobre todo prótasis (pero también apódosis). Hay que observar que en su desarrollo hacia el subjuntivo, los modos del camino modal genuinos coinciden con modos que siguen el camino modal por contaminación: los dos tipos de formaciones adquieren la función subjuntiva en determinados contextos sintácticos especificados previamente. Sin embargo, mientras que el primer grupo lo hace de manera conforme a su naturaleza modal original expandiendo su alcance modal (véase el uso del verbo modal should 'debe, debería, es probable' en frases condicionales del tipo Should it rain, we will stay at home 'Si llueve, nos quedaremos en casa'), el segundo lo hace a través de la asimilación del significado del contexto sin introducir ningún elemento semántico modal propio (véase, por ejemplo, el uso del imperfecto en las prótasis condicionales contrafactuales en francés: Si j'avais de l'argent je l'achèterais 'Si tuviese dinero, lo compraría').

Debe resaltarse que la vida gramatical de los grams modales está estrechamente relacionada con el significado de futuro. Normalmente, una expresión modal -cualquiera que sea su origen y camino modal específico- adquiere en la etapa más avanzada el valor temporal de futuro. En una etapa aún más avanzada, el futuro (cualquiera sea su origen) puede reducirse a usos sintácticamente dependientes y a valores epistémicos, lo que conduce a su paulatina conversión en un subjuntivo ${ }^{33}$.

${ }^{31}$ De hecho "the subordinating uses show up very late on the grammaticization path. In fact, after the generalization of subordinating uses, the only further development for such grams is their gradual loss from the language" (Bybee, Perkins y Pagliuca, The Evolution of Grammar, pág. 241).

32 Bybee, Perkins y Pagliuca, The Evolution of Grammar, págs. 217-218.

${ }^{33}$ Bybee, Perkins y Pagliuca, The Evolution of Grammar, pág. 274. 
Por consiguiente, el desarrollo modal genuino establece ciertas regularidades en la evolución de los modos: los grams evolucionan a través de cuatro etapas mayores (modo de agente $>$ modo de hablante / modalidad epistémica $>$ futuro $>$ subjuntivo) y el uso subjuntivo (en frases subordinadas o condicionales con valor modal generalizado y no-indicativo) constituye la etapa final de todos los caminos modales. Por tanto, y especialmente porque la segunda regularidad es empíricamente válida tanto para caminos modales genuinos como para caminos modales por contaminación, es posible que el patrón semántico general también se permita para los modos del trayecto por contaminación: una vez contaminado, el gram seguiría la matriz evolutiva regular.

Aunque el patrón general evolutivo común a los caminos evolutivos pueda resultar útil para diseñar el mapa semántico de un gram que resulte del camino modal por contaminación, existen tres problemas que dificultan en cierta medida su aplicación.

En primer lugar, los caminos modales genuinos presentan dos complicaciones. Por una parte, los valores deónticos (imperativos), de modalidad epistémica y de futuro pueden mostrar una secuencia disimilar dependiendo del tipo del input modal exacto. Si el input es una expresión de capacidad, entonces la modalidad epistémica se expande en el futuro. Si la trayectoria surge de una locución que indica deseo, es el futuro el que lleva a valores deónticos o epistémicos ${ }^{34}$. Finalmente, si el origen se encuentra en una expresión de obligación, el valor deóntico produce una extensión en el significado epistémico y éste, a continuación, en el de futuro. Por otra parte, no deben darse todas las etapas principales (sobre todo de modalidad epistémica y de futuro) durante el desarrollo. Por ejemplo, en el camino modal de obligación (que como veremos es el más relevante para el yiqtol corto), el valor imperativo (uno de los significados modales de hablante) conduce directamente hacia el subjuntivo, mientras que el futuro se genera a través del valor de intención que, al igual que el imperativo (y otros matices deónticos de hablante), surge de la obligación agentiva $^{35}$. Por tanto, más que de una trayectoria lineal se trata de una red con múltiples nodos y extensiones paralelas.

\footnotetext{
${ }^{34}$ Bybee, Perkins y Pagliuca, The Evolution of Grammar, pág. 240.

${ }^{35}$ Bybee, Perkins y Pagliuca, The Evolution of Grammar, pág. 240.
} 
En segundo lugar, existe un problema adicional con modos que siguen la trayectoria modal por contaminación. Dependiendo de los contextos lexical, sintáctico o pragmático en que se haya producido la contaminación original, las construcciones gramaticales pueden aparecer, aparentemente, en cualquier lugar del camino modal general que corresponde a las etapas semánticas consecutivas mencionadas previamente. Así pues, la contaminación puede darse en un contexto que conduzca directamente a la fase de modalidad de hablante (órdenes), en un entorno que produzca un valor futuro (apódosis factual real) o en una situación que conduzca a subjuntivos (frases subordinadas).

Por último, los diversos estudios tipológicos indican que el desarrollo de los grams modales se encuentra profundamente condicionado por el sistema en el que éste se produce y que la variedad de posibles evoluciones es más grande que en el caso de los caminos resultativo (hacia pasados) o imperfectivo (hacia presentes). Como hemos mencionado, ya que las lenguas son sistemas complejos con una serie de leyes que operan simultáneamente, un elemento de este sistema puede a veces alejarse de lo estadísticamente previsto. Esta situación es particularmente visible en el desarrollo de los modos con sus innumerables matices.

Toda esta discusión indica que para proponer un mapa correcto (o por lo menos plausible) de un gram de camino modal por contaminación -en nuestro caso, del yiqtol corto- es necesario conocer previamente el contexto original de la contaminación. Conociendo este origen podremos determinar el lugar en el que el gram se unió al camino modal (contexto para desarrollar modalidades de agente, hablante, futuro o subjuntivo) y la posible secuencialidad de los valores deóntico, epistémico y futuro. El origen de la contaminación también nos indicará ciertas idiosincrasias del sistema en el que surgió y se expandió la formación, idiosincrasias que, como se ha explicado, son capaces de condicionar fuertemente la evolución de este gram. Para determinar el contexto (o contextos) original de dicha contaminación es necesario examinar más a fondo los datos ofrecidos por la lingüística semítica (y afroasiática) comparado-diacrónica. 


\subsubsection{Lingüística semítica comparada}

Tal como está reconocido, en la lengua acadia existen dos formaciones basadas en la morfología del *yaqtul (-iprus) que se relacionan genéticamente con el yiqtol corto del hebreo bíblico: liprus y ayyiprus. La primera construcción, denominada 'precativo', expresa principalmente valores yusivos (deóntico afirmativo con la $3^{\mathrm{a}}$ persona,) y cohortativos (deóntico o exhortaciones dirigidas a la $1^{a}$ persona). Por lo tanto, el gram suele indicar órdenes (usualmente débiles) y deseos. Desde el punto de vista sistémico, el iprus constituye el paradigma supletivo imperativo para la $1^{\mathrm{a}} \mathrm{y}$ $3^{\text {a }}$ personas, para las que no existe un imperativo del tipo purus. Además, el liprus de la $1^{\text {a }}$ persona aparece en frases interrogativas con valor deliberativo, así como con algunas partículas que tienen una interpretación epistémica, contrafactual o irreal, como por ejemplo tuša (la partícula contra-asertiva o de refutación) o man (una partícula contrafactual) ${ }^{36}$.

Por su parte, liprus aparece en prótasis de frases condicionales nomarcadas (parataxis) presentando un valor epistémico de posibilidad o probabilidad e introduciendo la condición factual y real, frecuentemente concesiva: even if it occurs / should it occur ${ }^{37}$. En apódosis de frases condicionales cuyas prótasis están marcadas por šumma, liprus proporciona el valor deóntico de hablante consistente con su uso prototípico directivo ${ }^{38}$. Lo mismo ocurre en construcciones con dos - $m a$, donde liprus aparece en apódosis con valor deóntico ${ }^{39}$. Es importante observar que en una prótasis el gram tienen valor epistémico, mientras que en una apódosis su significado es más bien deóntico de hablante, similar al uso independiente. En una secuencia de proposiciones con formas verbales modales como liprus (precativo), purus (imperativo) o lā taparras (imperativo negativo), el liprus de

${ }^{36}$ N. Wasserman, Most Probably: Epistemic Modality in Old Babylonian (Winona Lake 2012) págs. 94, 99, 102-103 y 117-126. Para otras definiciones de este lexema (como potencialidad irreal; cf. W. vON SodEn, Grundriss der akkadischen Grammatik [Rome 1952] pág. 385) véase Wasserman, Most Probably: Epistemic Modality in Old Babylonian, pág. 95.

${ }^{37}$ El gram ayyiprus (véase el apartado siguiente) constituye la variante negativa: should not occur (E. CoHEN, Conditional Structures in Mesopotamian Old Babylonian [Winona Lake 2012] págs. 90-93).

${ }^{38}$ Cohen, Conditional Structures, págs. 73 y 77.

${ }^{39}$ CoHen, Conditional Structures, págs. 94-95. 
la segunda frase (o de las frases siguientes), empleado asindéticamente o introducido por la partícula $m a$, expresa valor de finalidad.

Debe resaltarse que liprus es frecuente en la $1^{\mathrm{a}}$ y $3^{\mathrm{a}}$ persona, mientras que el uso con la $2^{\mathrm{a}}$ persona es muy excepcional y aparece sólo en usos dependientes o subordinados ${ }^{40}$. En cuanto a su morfología, en la mayoría de los casos el precativo acadio está marcado por el prefijo $l$ - (si la forma verbal empieza por una vocal), aunque si el verbo empieza por una consonante (especialmente en la $1^{\text {a }}$ persona del plural niprus) el morfema precativo aparece como una partícula proclítica independiente $i$ (en babilonio) o $l \bar{u}$ (en asirio $)^{41}$.

Otra formación relacionada con el yiqtol corto, y por tanto sucesora del *yaqtul modal proto-semítico, es el vetitivo ayyiprus, que expresa deseos negativos con todas las personas y constituye, por tanto, una variante negativa del precativo así como un alternativa menos categórica del prohibitivo lā taparras. Las formas de $1^{\mathrm{a}}$ persona son esporádicas. La diferencia entre vetitivo e imperativo es de doble naturaleza. Primero, tal como se ha mencionado, el vetitivo es una expresión atenuada y se emplea para deseos o exhortaciones negativas y no para órdenes sensu stricto. Además, el vetitivo es menos frecuente que el prohibitivo, siendo más común en dialectos más antiguos ${ }^{42}$. Hay que observar que, al contrario del precativo liprus, la partícula de ayyiprus es semi-gramaticalizada como prefijo. Aunque en la mayoría de los casos funciona como un prefijo, cuya forma depende del fonema inicial del verbo conjugado y se presenta como ayy- o $\bar{e}-$, también puede ser independiente. Esta segunda opción ocurre en asirio en la expresión con $\bar{e} l \bar{a}$ así como en textos más antiguos en los que $\bar{e}$ puede preceder al parsāku. De hecho, en pocas ocasiones se emplea la partícula $\bar{e}$ como lexema independiente de interjección “ ‘no! ${ }^{43}$.

Finalmente se debe observar que el iprus simple puede hallarse en prótasis condicionales con šumma 'si' con valor hipotético de causa lógico-temporal (además del valor de anterioridad) o en el caso de los verbos

${ }^{40}$ Kouwenberg, The Akkadian Verb and its Semitic Background, pág. 212.

${ }^{41}$ J. Huehnergard, «Proto-Semitic and Proto-Akkadian», en The Akkadian Language in its Semitic Context, eds. G. Deutscher y N. J. C. Kouwenberg (Leiden 2006) págs. 1-18; N. J. S. Kouwenberg, The Akkadian Verb and its Semitic Background, pág. 213.

${ }^{42}$ Kouwenberg, The Akkadian Verb and its Semitic Background, págs. 218-219.

${ }^{43}$ Kouwenberg, The Akkadian Verb and its Semitic Background, pág. 217. 
edûm e išûm donde, apareciendo con la partícula modal lū, expresa valor imperativo y precativo.

En árabe, la formación equivalente al yiqtol corto hebreo y a los grams acadios mencionados previamente es el yaqtul modal, llamado 'yusivo' o 'apocopado'. El yaqtul modal se emplea principalmente con valor deóntico y "condicional". En función deóntica afirmativa esta formación se emplea como yusivo (deóntico de la $3^{\mathrm{a}}$ persona) y cohortativo (con la $1^{\mathrm{a}}$ persona). En función deóntica negativa, yaqtul se usa muy frecuentemente como imperativo negativo. Una vez más, el gram proporciona el paradigma imperativo para las personas $\left(1^{\mathrm{a}}\right.$ y $\left.3^{\mathrm{a}}\right)$ y contextos (negativo) que no tienen una forma imperativa propia. En ocasiones yaqtul-especialmente a continuación de un imperativo- puede aparecer en frases finales ${ }^{44}$. En las funciones yusiva y cohortativa, el gram suele venir precedido por la partícula $l$ - o por su extensión $f a l^{45}$. Otro uso principal del yaqtul modal corresponde a su empleo en frases condicionales (prótasis y apódosis), introduciendo situaciones factuales reales y contrafactuales reales o irreales. El yaqtul de la apódosis -al igual que el yaqtul modal- puede estar precedido por las partículas $l$ - y $\mathrm{fal}^{46}$. En algunos dialectos árabes antiguos, el yaqtul se emplea en frases subordinadas detrás de las partículas 'an 'que' y lan (lā-'an) en función de subjuntivo en lugar del yaqtula que regularmente desempeña esta función en el árabe clásico ${ }^{47}$.

En gə‘əz, la antigua lengua etíope, yəngär -el gram genéticamente relacionado con el yiqtol corto hebreo y con sus equivalentes en las lenguas semíticas mencionadas- ofrece usos muy similares a los de sus homólogos hebreos, acadios y árabes. La construcción se emplea con valor deóntico en la $3^{\mathrm{a}}$ (yusivo) y la $1^{\mathrm{a}}$ personas (cohortativo), así como con la $2^{a}$ persona en función deóntica negativa (imperativo negativo). Además el gram aparece en frases subordinadas, especialmente finales, con fun-

\footnotetext{
${ }^{44}$ LIPIŃSKI, Semitic Languages Outline of a Comparative Grammar, pág. 365.

${ }^{45}$ J. A. Haywood y H. N. Nahmad, A New Arabic Grammar (London 1965) pág. 129.

${ }^{46}$ W. Wright, Arabic Grammar (Mineola 1896-1898/2005) págs. 35-41; J. A. Haywood y H. N. Nahmad, A New Arabic Grammar, págs. 128-129.

${ }^{47}$ LIPIŃSKI, Semitic Languages Outline of a Comparative Grammar, pág. 358.
} 
ción subjuntiva ${ }^{48}$. Otras lenguas etíopes muestran una situación parecida. En tigre, el gram, además de los típicos usos deónticos (yusivo), aparece en frases interrogativas retóricas con función dubitativa, mientras que en frases subordinadas finales precedido por 'agal 'para que' funciona como subjuntivo $^{49}$. En Mansa' tigre, una lengua etíope moderna del norte, el denominado "yusivo" puede venir precedido por la preposición ’agal y seguido por el pronombre copulativo tu 'él (es)', expresando futuro sin connotaciones modales (Fağər Baṣa' 'əgal nigis tu 'Mañana iremos a Massawa' $)^{50}$. La posibilidad de emplear el "yusivo" como futuro también se da en los dialectos gurage occidentales, donde el futuro se expresa regularmente a través del gram sucesor del *yaqtul modal, acompañado por

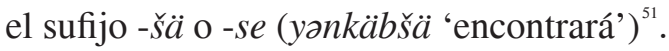

Finalmente, el árabe moderno del sur emplea un gram genéticamente relacionado con el yiqtol corto con dos funciones principales: como yusivo (significado deóntico) y como subjuntivo. De hecho, las lenguas mehri y harsūsi derivan sus subjuntivos del antiguo yaqtul modal, tal como era el caso en gə'əz.

Las evidencias relacionadas con el yiqtol corto hebreo, sus homólogos en otras lenguas semíticas y, por tanto, el *yaqtul modal proto-semítico, pueden completarse por datos aportados por algunas lenguas afroasiáticas. Es muy posible que lenguas libio-beréberes (kabyle y tarifit) incluyan un gram genéticamente relacionado con el *yaqtul proto-semítico modal y sus sucesores en lenguas semíticas antiguas o modernas $^{52}$. En concreto, en el tarifit la formación analógica tiene valor deóntico, apareciendo con la $3^{\mathrm{a}}$ persona (yusivo: a $\underline{d}$-yək $\underline{k} \mathrm{si}$ 'debería coger') y $2^{\text {a }}$ persona (deóntico débil: at-ta kssid 'deberías coger'). El gram también se atestigua en frases finales con función subjuntiva (yəruh a $a \underline{d}$ yəg்ar 'se fue para que pudieras estudiar') ${ }^{53}$. Según Kienast, en el beré-

${ }^{48}$ S. Weninger, «Old Ethiopic», en The Semitic Languages, ed. S. Weninger (Berlin 2011) págs. 1124-1142: 1121, 1131 y 1135.

${ }^{49}$ LiPIŃsKI, Semitic Languages Outline of a Comparative Grammar, pág. 356.

${ }^{50}$ LIPIŃsKI, Semitic Languages Outline of a Comparative Grammar, págs. 349 y 356.

${ }^{51}$ LiPIŃsKI, Semitic Languages Outline of a Comparative Grammar, pág. 350.

${ }^{52}$ Lipiński, Semitic Languages Outline of a Comparative Grammar, pág. 336.

${ }^{53}$ LiPIŃsKI, Semitic Languages Outline of a Comparative Grammar, pág. 356. 
ber moderno el gram ifres es una forma que originalmente equivalía al *yaqtul modal y no-modal del semítico. En concreto, el ifres -opuesto al ifarres (cf. iparras en acadio)- tiene dos funciones: modal y hecho simple $^{54}$. Como hecho simple, el gram equivale a un pretérito o aoristo (cf. iprus acadio) $^{55}$. Como una forma modal, el ifres funciona como un yusivo (deóntico dirigido a la $3^{\mathrm{a}}$ persona), precativo (variante deóntica negativa), condicional (en frases condicionales) y subjuntivo (en frases finales). Además, el gram se emplea como futuro ${ }^{56}$. En libio antiguo, por razones sistémicas y paradigmáticas, el ifres modal permaneció como tal (probablemente bajo la influencia del imperativo efres), mientras que el ifres "de hecho simple" (Enfaches Faktum) tomó la forma con vocalización $a / a$, es decir ifräs ${ }^{57}$. Además, la lengua bedya del grupo cusita presenta varios grams construidos con el elemento $d b i l$, parecido al * qtVl semítico presente en el *yaqtul modal ono modal, y sus sucesores como el yiqtol corto y wayyiqtol en hebreo. En todos estos casos, el bedja muestra una relación entre el perfecto o pasado por una parte y la modalidad por la otra: yi-dbil funciona como un pretérito, $i i$-dbíl como pasado y $i i$ - $d b l$ (morfológicamente idéntico al pasado pero con diferencia en acentuación) como yusivo (optativo) ${ }^{58}$.

Teniendo en cuenta la discusión previa, se puede proponer la siguiente naturaleza del *yaqtul modal proto-semítico. En primer lugar, su presencia en todos los subgrupos de la familia semítica indica que el *yaqtul

${ }^{54}$ KIENAST, Historische semitische Sprachwissenschaft, pág. 560.

${ }^{55}$ Kienast, Historische semitische Sprachwissenschaft, pág. 558.

${ }^{56}$ KIENAST, Historische semitische Sprachwissenschaft, págs. 558-560.

${ }^{57}$ KIENAST, Historische semitische Sprachwissenschaft, págs. 560, 569 y 571.

${ }^{58}$ KIENAST, Historische semitische Sprachwissenschaft, pág. 604, y LiPIŃsKI, Semitic Languages Outline of a Comparative Grammar, pág. 380. Se puede mencionar también que el egipcio clásico medio presenta una morfología $s \underline{d m} . f$ que, al igual que el *yaqtul proto-semítico, funciona como un perfecto-perfectivo-pasado (diacronía resultativa) y yusivo-optativo (diacronía modal). En frases afirmativas $s \underline{d} m . f$ se emplea como pasado narrativo (aunque $s \underline{d m} . n . f$ es una forma mucho más común). Sin embargo, en frases negativas como $n(n) s \underline{d m} . f$, la forma aparece comúnmente, siendo la equivalente del $s \underline{d} m . n . f$ afirmativo (A. DE BuCK, Grammaire élémentaire du moyen égyptien [Leiden 1952] págs. 66-74). Además, hay otro tipo de $s \underline{d m} . f$ que regularmente expresa deseos y órdenes, funcionando como yusivo u optativo (DE BuCK, Grammaire élémentaire du moyen égyptien, págs. 71-72). 
corto modal era sin duda una categoría proto-semítica bien establecida y gramaticalizada ${ }^{59}$. En segundo lugar, la especificación funcional de los dos tipos de morfología sucesora *yaqtul (i.e. en el perfecto/pasado y en el gram modal) en época muy antigua, su posible diferenciación en cuanto a la acentuación en *yáqtul y *yaqtúl $l^{60}$ y un bien generalizado (aunque opcional) uso del yaqtul con partículas modales en lenguas clásica (véase a continuación en este apartado), sugieren conjuntamente que el *yaqtul modal y el *yaqtul del camino resultativo se habían bifurcado en dos grams independientes en el proto-semítico, es decir, que en esta época ya constituían dos formaciones distintas. Así pues, el *yaqtul modal protosemítico (*yaqtúl) es una categoría independiente y no una mera variante modal de la otra morfología del tipo *yaqtul (*yáqtul). El proceso de contaminación estaba fuertemente desarrollado, por lo que el gram se había convertido en un modo sensu stricto.

Entre todos los usos ofrecidos por los sucesores del *yaqtul modal en lenguas antiguas (acadio, hebreo, árabe clásico y gə‘əz) predomina el significado deóntico dirigido a la $3^{\mathrm{a}}$ (yusivo) y $1^{\mathrm{a}}$ personas (cohortativo), así como el valor deóntico negativo (especialmente de la $2^{\text {a }}$ persona empleado como imperativo negativo). Menos común es su uso en función de finalidad, en calidad de subjuntivo, y el valor de futuro. Sin embargo, estos dos significados ganarán peso y se generalizarán en varias lenguas modernas. Por lo tanto, los valores ofrecidos en lenguas más antiguas sugieren que el potencial semántico del *yaqtul modal proto-semítico incluía los siguientes componentes prototípicos: deóntico afirmativo (con la $3^{\mathrm{a}}$ y $1^{\mathrm{a}}$ persona) y deóntico negativo (con todas las personas, aunque especialmente con la $2^{\mathrm{a}}$ persona). Puesto que el imperativo semítico solo se refiere a la $2^{\mathrm{a}}$ persona en contextos afirmativos, el *yaqtul modal podría haber llegado a propor-

${ }^{59}$ R. Hetzron, «The Evidence for Perfect *YÁQTUL and Jussive *YAQTÚL in Proto-Semitic», Journal of Semitic Studies 14 (1969) págs. 1-21; LiPIŃski, Semitic Languages Outline of a Comparative Grammar, págs. 102 y 344; KIENAST, Historische semitische Sprachwissenschaft, y L. Kogan, «Proto-Semitic Phonetics and Phonology», en The Semitic Languages, ed. S WenINGER (Berlin 2011) págs. 54-151: 125.

${ }^{60}$ Hetzron, «The Evidence for Perfect *YÁQTUL and Jussive *YAQTÚL in ProtoSemitic»; R. L. GoERwITZ «The Accentuation of the Hebrew Jussive and Preterite», Journal of American Oriental Society 112 (1992) págs. 198-203; Lipiński, Semitic Languages Outline of a Comparative Grammar, pág. 102, y Kogan, «Proto-Semitic Phonetics and Phonology», pág. 125. 
cionar un paradigma supletivo de imperativo ya en época proto-semítica. Aunque los dos valores de finalidad (subjuntivo) y de futuro podían incluirse en el potencial semántico del gram en el proto-semítico, es probable que lo hicieran de una manera no prototípica. Entre los dos, el valor final podría haber sido más regularizado (ya que está bastante más establecido en las lenguas clásicas que el uso futuro). Los dos se limitaban probablemente a contextos dependientes: frases condicionales o subordinadas. Consecuentemente, en la semántica del gram el significado deóntico parece ser el más original y primario (prototípico y plenamente semantizado en el proto-semítico). El valor de finalidad era secundario (menos prototípico y parcialmente semantizado), mientras que el uso como futuro era terciario (no-prototípico y básicamente pragmático).

Los datos semíticos también indican que los sucesores del *yaqtul modal están acompañados, con frecuencia abrumadora, por partículas modales (deónticas afirmativas o negativas) proclíticas o morfemas que descienden de dichas partículas. Por tanto, el origen de estas partículas o morfemas puede ser decisivo para determinar aún mejor el contexto original del cual surgió el *yaqtul modal deóntico, es decir, frases deónticas de hablante tal como se ha propuesto en el apartado anterior.

Hemos visto que existen dos tipos principales de partículas que acompañan a los sucesores del *yaqtul modal. En el uso afirmativo estos grams incorporan frecuentemente prefijos de tipo " $l$ " $(l-, l \bar{u}, l i$ y sus variantes; por ejemplo, en acadio, ugarítico [aunque de una manera infrecuente], fenicio, árabe, gə ‘əz, amhárico, gurage oriental, árabe moderno del sur ${ }^{61}$; así como, menos comúnmente, $i$ (en función cohortativa en acadio) ${ }^{62}$, mientras que en uso negativo se emplean partículas negativas, de las cuales tres son igualmente posibles: $l \bar{a}$ (árabe), 'al (hebreo, ugarítico, fenicio) y $e y / \bar{e}$ (acadio $a y / e$, gə‘ว 'ว ' $)$.

En cuanto a las partículas del contexto afirmativo, es muy plausible que todas las marcas de tipo $l$ - desciendan de un mismo lexema modal (o de un grupo de lexemas modales relacionados). Por ejemplo, Kou-

${ }^{61}$ KIENAST, Historische semitische Sprachwissenschaft, págs. 263-267. A veces aparece el prefijo $n$ - en harari y otros dialectos del gurage (LIPIŃSKI, semitic Languages Outline of a Comparative Grammar, pág. 375).

${ }^{62}$ KIEnAst, Historische semitische Sprachwissenschaft, pág. 264. 
wenberg $^{63}$ relaciona de manera convincente el lexema asertivo $l \bar{u}$ con la partícula precativa $l \bar{u} / l-$ y explica esta relación por el diferente grado de gramaticalización ligado a la diferencia en frecuencia y función. El precativo es una forma más gramaticalizada o especializada del asertivo modal $l \bar{u}$ a través de la clitización ${ }^{64}$. Por tanto, el liprus acadio sería resultado de la gramaticalización del lexema independiente $l \bar{u}^{65}$. Es importante observar que las partículas $l-, l \bar{u}$ y $l i$ (que se emplean con los sucesores del *yaqtul modal) expresan como tales la idea modal de contrafactualidad o de énfasis asertivo y en varias lenguas semíticas aún pueden emplearse en frases no-verbales o con otras formas del verbo para expresar el valor deóntico de hablante del tipo yusivo o cohortativo (véase, por ejemplo, $l \bar{u}$ en acadio, que se usa con el parsāku ${ }^{66}$.

Puesto que en varias lenguas semíticas clásicas suele aparecer alguna variante de la partícula modal de tipo "l" con los sucesores del *yaqtul modal, su empleo con éste podría haber existido (y ser extendido) ya en el proto-semítico. Se trataría sin embargo de una partícula todavía independiente y posiblemente opcional. En lenguas posteriores se vería el incremento de gramaticalización de la partícula modal, su clitización

${ }^{63}$ Kouwenberg, The Akkadian Verb and its Semitic Background, pág. 216.

${ }^{64}$ J. Huennergard («Asseverative *la- and Hypothetical *lü/law in Semitic», Journal of the American Oriental Society 103 [1983] págs. 569-593: 588-589) reconstruye una partícula independiente $* \bar{u} /$ law (con valor contra-factual e hipotético) para $l \bar{u}$, y una partícula proclítica *la- asertiva como predecesores del precativo en $l \bar{u} / l$. D. TESTEN («The East Semitic Precative Paradigm», Journal of Semitic Studies 38 [1993] págs 1-13, y Parallels in Semitic Linguistics: The Development of Arabic la- and Related Semitic Particles [Leiden 1998] págs. 124-129) propone que el protosemítico tenía una partícula *l de la que deriva el precativo.

${ }^{65}$ I. M. Diakonoff, Afrasian Languages (Moscow 1988) pág. 102; Kienast, Historische semitische Sprachwissenschaft, págs. 263-264, y KOUWENBERG, The Akkadian Verb and its Semitic Background, pág. 215. Ciertamente, dado que el resultado de esta gramaticalización es parcialmente diferente en diversos dialectos acadios, es muy probable que el proceso empezara después de la fragmentación del protoacadio y por tanto sea posterior al protosemítico (Kouwenberg, The Akkadian Verb and its Semitic Background, pág. 216).

${ }^{66}$ D. O. EDZARD, «Die Modi beim älteren akkadischen Verbum», Orientalia 42 (1973) págs. 121-141: 129-130; Huennergard, «Asseverative *la- and Hypothetical *lū/law in Semitic»; Testen, Parallels in Semitic Linguistics, págs. 95-134; E. Cohen, The Modal System of Old Babylonian (Winona Lake 2005) págs. 17-68; N. J. S. KouwEnBERG, The Akkadian Verb and its Semitic Background, págs. 213-215. 
$y$, finalmente, prefijación como un morfema dependiente ${ }^{67}$. En cualquier caso de trata de un recurso muy antiguo, probablemente proto-semítico, como se ha visto arriba.

En cuanto a las partículas del contexto negativo, aunque los descendientes del *yaqtul modal se emplean regularmente en función deóntica negativa (prohibitiva como imperativo negativo o vetitiva como precativo negativo, es decir, un tipo de imperativo más atenuado), existe una variedad más grande de partículas. Con bastante certeza ${ }^{68}$, el imperativo proto-semítico no se empleaba en frases negativas. Tal como hemos visto, la mayoría de las lenguas usaban para el prohibitivo (deóntico negativo fuerte, dirigido especialmente a la $2^{\mathrm{a}}$ persona) el sucesor del *yaqtul modal. Sin embargo en acadio para el imperativo negativo se emplea iparras precedido por la partícula negativa $l \bar{a}$ ' ‘no!', mientras que el sucesor del *yaqtul introduce ordenes negativas suaves. Tal como se ha indicado previamente, existen tres partículas que aparecen con los sucesores del *yaqtul modal negativo: lā (árabe), 'al (hebreo, ugarítico, fenicio) y ey/e (acadio ay/e y gə ‘zz ' $\bar{\imath}$ ). La relación entre $l \bar{a}$ y 'al es incierta y usualmente se trata estas partículas como entidades distintas ${ }^{69}$. El origen de la partícula del vetitivo acadio está relacionado con la negación ' $i$ en ga 'əz o con el lexema interrogativo acadio ay ¿¿ónde?' ${ }^{70}$, que podría haberse gramaticalizado como una negación, lo cual no es extraño tipológicamente. Es importante señalar que ninguna de estas partículas se convirtió en morfema dependiente, es decir, en un sufijo. Incluso en acadio ay/e se ha clitizado solo parcialmente y aún puede aparecer de forma independiente. Además, al igual que las variantes de la partícula afirmativa "l", todas las partículas negativas pueden darse en frases nominales o verbales con otros grams, a menudo como lexemas independientes, introduciendo el valor deóntico nega-

${ }^{67}$ Sin embargo, la gramaticalización no habría procedido de la misma manera en todas lenguas. De hecho, en hebreo el yiqtol corto afirmativo no necesita ninguna marca modal explicita.

${ }^{68} \mathrm{~J}$. Tropper, Altäthiopisch. Grammatik des Ge'ez mit Übungstexten und Glossar (Münster 2002) pág. 148.

${ }^{69}$ KIENAST, Historische semitische Sprachwissenschaft.

${ }^{70}$ Lipiński, Semitic Languages Outline of a Comparative Grammar, págs. 356 y 456, y Kouwenberg, The Akkadian Verb and its Semitic Background, pág. 218. 
tivo explícito ${ }^{71}$. En consecuencia, aunque el uso deóntico negativo sea muy antiguo -ya que aparece en todas las lenguas, incluidas las más antiguas- la clitización de lexema deóntico negativo es menos marcada que en la función deóntica afirmativa y el abanico de partículas resulta más grande.

En conclusión, dado el potencial semántico de los sucesores del *yaqtul modal y la naturaleza de las partículas con las que se presentan dichos sucesores (especialmente sus significados modales de hablantes explícitos), es muy probable que el contexto deóntico afirmativo (orden o deseo dirigido a la $3^{\mathrm{a}}$ y $1^{\mathrm{a}}$ personas) y deóntico negativo (deseo $\mathrm{u}$ orden dirigido a cualquier persona, pero especialmente a la $2^{\mathrm{a}}$ persona) sean cronológicamente primarios $^{72}$. Es imposible precisar con certeza cuál de estas dos funciones es más original. Se puede conjeturar que lo sea el uso afirmativo, ya que su gramaticalización y regularidad son ligeramente mayores. Sin embargo, la falta de una completa morfologización de las locuciones compuestas por partículas deónticas negativas y los sucesores del *yaqtul modal, así como la generalización de tres variantes distintos de dichas partículas, pueden corresponder a otros fenómenos. Otros usos, como el valor de finalidad en frases dependientes y de futuro (incluido el uso en frases condicionales) parecen ser posteriores, siendo extensiones modales de los usos modales primarios. Tal como se ha explicado, el significado de finalidad parece ser secundario, mientras que el futuro es terciario, y por eso bastante menos prototípico en el proto-semítico. El valor deóntico de hablante, prototípico ya en época proto-semítica y el más original en el proceso de contaminación, ha sido introducido a causa del empleo del gram con partículas modales que ofrecían ese significado deóntico (afirmativo o negativo) de una manera explícita. Este valor era inherente a las partículas y constituyó el origen de la contaminación.

\footnotetext{
${ }^{71}$ KIENAST, Historische semitische Sprachwissenschaft, pág. 264, y KoUwEnBERG, The Akkadian Verb and its Semitic Background.

${ }^{72}$ Las evidencias acadias y árabes sugieren que desde una época muy antigua el valor de orden y deseo podría haberse dirigido a la $1^{a}$ persona (el valor cohortativo). Sin embargo, la tipología sugiere que este uso podría ser un desarrollo secundario, una extensión de la $3^{\mathrm{a}}$ y $2^{\mathrm{a}}$ personas a la $1^{\mathrm{a}}$ persona (véase el uso del participio perfecto en lenguas eslavas que se emplea para introducir órdenes a la $3^{\mathrm{a}}$ y $2^{\mathrm{a}}$ persona [afirmativos y negativos] pero no a la $1^{\mathrm{a}}$ persona). Ya que el yiqtol corto hebreo no ofrece ejemplos de $1^{a}$ persona, no hay necesidad de precisar la cronología (secuencialidad) de este proceso.
} 


\subsubsection{El mapa del yiqtol corto en hebreo bíblico}

Los datos comparados-diacrónicos indican que la primera contaminación del *yaqtul proto-semítico debe haber ocurrido en el contexto deóntico de hablante, tanto afirmativo como negativo. Fue en ese entorno pragmático y sintáctico en el que un gram originalmente no modal habría adquirido valor modal. Por tanto, nos enfrentamos a un camino secundario del tipo deóntico, ya que fue inducido por contaminación.

Tal como se ha expuesto, el camino deóntico conduce desde la modalidad de obligación de agente hacia la modalidad deóntica de hablante (imperativo, yusivo y posiblemente cohortativo, el lugar en el que el *yaqtul se incorporó al trayecto) y desde estos dos hacia usos subordinados de subjuntivo. Esta trayectoria se relaciona también con valores de la modalidad epistémica de probabilidad y de futuro que se sitúan, al igual que la modalidad de hablante, en la zona intermedia del trayecto. Sin embargo, el futuro se desarrolla desde el valor de intención, que desciende directamente de la obligación agentiva. Asimismo, el matiz de probabilidad epistémica suele derivar de la obligación agentiva de una manera inmediata. Por lo tanto, los dos usos (el epistémico y el futuro) no constituyen extensiones directas desde la modalidad de hablante ${ }^{73}$. Los tres subcaminos de la trayectoria deóntica (al igual que todos los desarrollos modales) conducen al subjuntivo. Durante la generalización como subjuntivo, el futuro e imperativo (así como el yusivo y cohortativo) aparecen primero en contextos de finalidad, mientras que la probabilidad se suele hallar en el entorno concesivo. En estos entornos de subordinación sintáctica, que son las etapas iniciales de la evolución de las construcciones subjuntivas, los grams aparecen al principio en frases introducidas por predicados armónicos. En particular, los grams que desvelan tendencia para adquirir el valor de finalidad suelen ser complementos de verbos que expresan órdenes o deseo ('ordenar' o 'querer'). Asimismo, existe una relación entre valores deónticos de hablante y el uso concesivo, dando lugar a un uso condicional, especialmente en prótasis.

La dirección y secuencia de expansión del potencial semántico predicho por los estudios tipológicos se corresponde con los datos compa-

${ }^{73}$ B ybee, Perkins y Pagliuca, The Evolution of Grammar, pág. 240. 
rados-diacrónicos y nos permite, por consiguiente, proponer el siguiente mapa semántico sincrónico del yiqtol corto hebreo desde la perspectiva de gramaticalización.

El significado deóntico de $2^{\mathrm{a}}$ y $3^{\mathrm{a}}$ persona, tanto afirmativo como negativo, constituye el centro del mapa: su origen diacrónico y conceptual. Dado que no es posible determinar cuál de los dos contextos deónticos fue primario (afirmativo o negativo), los dos deben presentarse como núcleos del mapa, del que habrían partido otros usos. Los valores finales son secundarios y desarrollados desde valores deónticos. En el caso del hebreo bíblico, el yiqtol corto de finalidad es una contextualización del yiqtol corto afirmativo (pues casi no hay ejemplos negativos del valor de finalidad) empleado en frases subordinadas y acompañado en casi todos los casos por el morfema $w a w^{74}$. Es importante observar que en los ejemplos del valor de finalidad, el yiqtol corto de frases dependientes sigue a predicados armónicos (o más bien parcialmente armónicos, ya que no hay ejemplos de verbos 'querer' u 'ordenar') como 'aconsejar' (Ex 18,19), 'pedir' (1Re 2,17), 'hablar a' (Nm 17,2), 'rezar a' (Ex 10,17, Ex 8,4, Nm 21,7), al igual que a predicados no-armónicos, especialmente a verbos que connotan la idea de 'dar', 'coger', 'traer' y verbos de movimiento. Esta segunda opción es mucho más común y se halla en un $76 \%$ de los casos, mientras el uso con verbos (casi-)armónicos aparece en un $24 \%$. Esto sugiere una gramaticalización relativamente profunda de la función de finalidad.

El significado de futuro -diacrónicamente más joven que los demás valores- parece constituir una extensión independiente desde el núcleo deóntico. Este valor podría estar ligado a un empleo probablemente más original, en apódosis condicionales. Ya que los usos futuros en lenguas más antiguas aparecen principalmente en frases condicionales (incluidas las apódosis, pero especialmente las prótasis) y que desde la perspectiva tipológica los futuros pueden descender de formaciones originalmente no-futuras empleadas en periodos condicionales factuales-reales, es muy plausible que el valor futuro del yiqtol corto hebreo haya nacido en un entorno apodótico. De hecho, los dos tipos del futuro,

${ }^{74}$ Recuérdese que mientras el $95 \%$ de los ejemplos con significado de finalidad emplea el WE-Syiqtol, el $25 \%$ del valor deóntico afirmativo también usa esta variante morfosintáctica. 
el independiente y el apodótico, se dan en hebreo bíblico. Aunque el uso en contextos condicionales apodóticos pudiese ser muy antiguo, su reinterpretación con valor futuro y su generalización en frases independientes son fenómenos bastante posteriores (al contrario, el valor futuro en prótasis parece ser más antiguo; compárese el uso del liprus acadio). En todo caso, el valor de futuro (en contextos distintos al de prótasis) es posterior al deóntico de hablante y, con mucha probabilidad, también al de la finalidad.

En consecuencia es posible diseñar el siguiente mapa del yiqtol corto hebreo basado en su propia matriz de gramaticalización, derivada de los datos sincrónicos (valores del gram en hebreo bíblico), evidencias comparadas-diacrónicas (el origen [pre]-proto-semítico, dada la naturaleza de los homólogos del yiqtol corto en otras lenguas) y los universales del trayecto modal de contaminación y del trayecto modal deóntico a partir de expresiones modales deónticas de hablante:

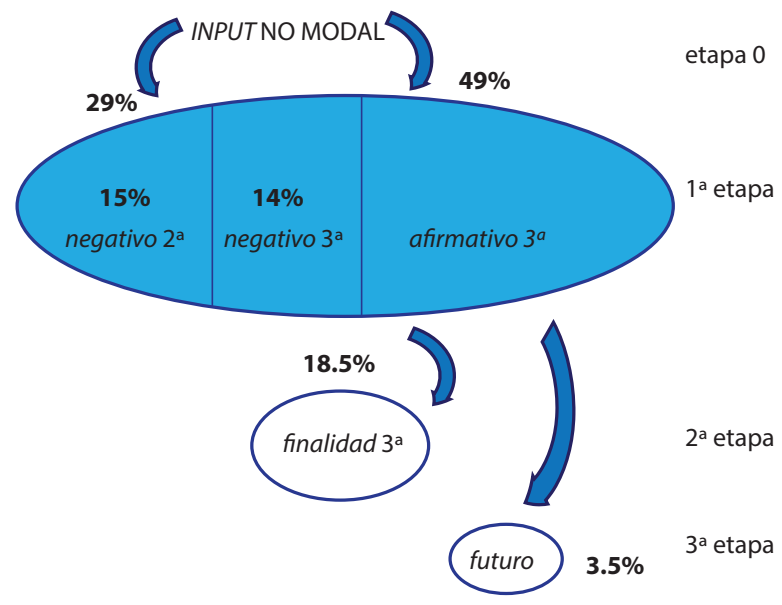

Gráfico 5: Mapa dinámico del yiqtol corto hebreo

El mapa propuesto en el Gráfico 5 puede recibir una representación aún más dinámica. En este nuevo modelo los significados se representan en el eje horizontal $x$ como etapas diacrónicas de gramaticalización. Las frecuencias de estos significados se indican en el eje vertical $y$. Los dos 
valores se relacionan produciendo la forma lineal de una onda. Este modelo tiene varias ventajas frente al modelo del Gráfico 5. En particular, plasma de manera elegante y sencilla toda la información cualitativa (significados o potencial semántico del gram) y cuantitativa (frecuencias o zonas de prototipicalidad y mayor semantización). Además, la naturaleza semántica del gram se representa como un ente coherente, puesto que la línea de la onda es continua. Esto hace referencia a que las sucesivas etapas de gramaticalización son difusas y se componen de una multitud de extensiones más microscópicas. El gram incorpora el valor categorizado en nuestro esquema como una etapa distinta a través de una variedad de etapas intermediarias: se trata de un continuum semántico que se dirige desde el origen diacrónico hacia el fin del gram en una lengua.



Gráfico 6: Onda del yiqtol corto

Esta representación proporciona una manera fácil de comparar el potencial semántico de los homólogos del yiqtol corto (tanto cualitativo como cuantitativo) en la familia semítica y seguir la evolución del *yaqtul modal en lenguas descendientes del proto-semítico. Dadas las leyes de gramaticalización, es de esperar que lenguas cronológicamente más antiguas exhiban una situación más conservadora (valores subjuntivos y futuros deberían estar menos marcados y menos semantizados), mientras que lenguas más jóvenes deberían proporcionar estados evolutivos más 
avanzados (los usos subjuntivos y futuros deberían generalizarse). Aunque, salvo error por nuestra parte, no dispongamos de datos exactos de otros idiomas, las lenguas semíticas muestran un progreso gradual desde un estado menos avanzado (prototipicalidad solo en zona 1) hacia estados más avanzados (las zonas 2 y 3 también llegan a ser prototípicas). Por ejemplo, el árabe clásico muestra un grado más avanzado en comparación con el hebreo o el acadio, ofreciendo un incremento significativo del uso del futuro. Asimismo, las funciones subjuntivas y futuras parecen encontrase más generalizadas en varias lenguas modernas (etíopes, árabe del sur o dialectos árabes) sugiriendo que el pico de la onda -en conformidad con la gramaticalización- se haya ido desplazando y que las regiones previamente no-semantizadas se hayan ido semantizado (vid. aptdo. 2.3.2).

\section{Conclusiones}

En este estudio hemos propuesto una definición dinámica del significado del yiqtol corto en hebreo bíblico, representando el gram como un mapa sincrónico de los valores que están relacionados cognitivamente, tanto de una manera conceptual como diacrónica. Este mapa exhibe una organización que es objetiva y empírica, puesto que se basa en estudios tipológicos (evoluciones de los grams modales en lenguas del mundo) y en el análisis comparativo-diacrónico (la historia del yiqtol corto o la evolución del *yaqtul desde el [pre-]proto-semítico hacia las lenguas semíticas atestiguadas, tanto antiguas como modernas). Se trata pues de un gram de camino modal por contaminación, contaminado en el contexto deóntico de hablante (afirmativo y negativo), extendido después a usos subordinados de finalidad y, a continuación, empleado como futuro (primero apodótico y luego independiente). La zona de prototipicalidad corresponde a usos deónticos. El valor de finalidad constituye el pico de prototipicalidad secundario, mientras que el significado de futuro es minoritario. Esto sugiere que los hablantes podían asociar el yiqtol corto con la expresión de matices deónticos de hablante. De esta manera, el gram, con toda su variedad de valores, se puede presentar como un fenómeno coherente por medio de una onda con zonas de mayor o menor prototipicalidad y, por eso, semantización. 
Aunque el mapa presente el potencial semántico del yiqtol corto en un momento dado y explique el gram como una entidad sincrónica, lo hace de manera dinámica. La formación no es un objeto estático sino un fenómeno evolutivo emergente; esa dinámica inherente se expresa a través de la onda direccional. Por consiguiente, la gramática deja de ser un sistema evolutivamente "detenido" y aparece tal como lo es en realidad: un sistema vivo donde el cambio y la potencialidad evolutiva constituyen conceptos fundamentales.

El modelo semántico del yiqtol corto indica además que el gram constituye, junto con weqatal, el subsistema de camino modal por contaminación. Las dos formaciones han surgido y adquirido sus valores a través de la contaminación modal. El yiqtol corto es un gram significativamente más antiguo, mientras que el weqatal es una formación nueva creada en la época post-proto-semítica y limitada en principio al cananeo. Se debe observar que aunque el weqatal sea un ejemplo de contaminación, el contexto original de la contaminación era bien distinto y correspondía a apódosis condicionales factuales-reales. Al contrario, los valores de finalidad y deónticos de hablante (imperativo, yusivo) constituyen extensiones secundarias ${ }^{75}$. Por tanto, las dos formaciones ofrecen un desarrollo semántico de dirección opuesta: el yiqtol corto desde el valor deóntico de hablante hacia el futuro a través de finalidad (subjuntivo), el weqatal desde el futuro (apodótico) hacia el deóntico de hablante a través de finalidad. Las direcciones opuestas de los dos grams están condicionadas por el contexto en el que se produjo la primera contaminación.

Recibido: $11 / 01 / 2016$

Aceptado: 15/04/2016

${ }^{75}$ Vid. Andrason, «The Dynamic Short yiqtol»; El sistema verbal hebreo en su contexto semítico, y «An Optative Indicative? A Real Factual Past?». 